\title{
The Molecular and Cellular Basis of Taste Coding in the Legs of Drosophila
}

\author{
Frederick Ling, ${ }^{1}$ Anupama Dahanukar, ${ }^{1,2}$ Linnea A. Weiss, ${ }^{1}$ Jae Young Kwon, ${ }^{1,3}$ and John R. Carlson ${ }^{1}$ \\ ${ }^{1}$ Department of Molecular, Cellular, and Developmental Biology, Yale University, New Haven, Connecticut 06520, ${ }^{2}$ Department of Entomology, Institute for \\ Integrative Genome Biology, University of California Riverside, Riverside, California 94720, and ${ }^{3}$ Department of Biological Sciences, Sungkyunkwan \\ University, Suwon, Gyeonggi-do 440-746, Korea
}

To understand the principles of taste coding, it is necessary to understand the functional organization of the taste organs. Although the labellum of the Drosophila melanogaster head has been described in detail, the tarsal segments of the legs, which collectively contain more taste sensilla than the labellum, have received much less attention. We performed a systematic anatomical, physiological, and molecular analysis of the tarsal sensilla of Drosophila. We construct an anatomical map of all five tarsal segments of each female leg. The taste sensilla of the female foreleg are systematically tested with a panel of 40 diverse compounds, yielding a response matrix of $\sim 500$ sensillum-tastant combinations. Six types of sensilla are characterized. One type was tuned remarkably broadly: it responded to 19 of 27 bitter compounds tested, as well as sugars; another type responded to neither. The midleg is similar but distinct from the foreleg. The response specificities of the tarsal sensilla differ from those of the labellum, as do $n$-dimensional taste spaces constructed for each organ, enhancing the capacity of the fly to encode and respond to gustatory information. We examined the expression patterns of all 68 gustatory receptors (Grs). A total of $28 \mathrm{Gr}-\mathrm{GAL} 4$ drivers are expressed in the legs. We constructed a receptor-to-sensillum map of the legs and a receptor-to-neuron map. Fourteen Gr-GAL4 drivers are expressed uniquely in the bitter-sensing neuron of the sensillum that is tuned exceptionally broadly. Integration of the molecular and physiological maps provides insight into the underlying basis of taste coding.

Key words: Drosophila; Gr; gustatory receptor; legs; physiology; taste

\section{Introduction}

Brillat-Savarin (1825) observed that "It is not easy to determine precisely what parts make up the organ of taste." Although not easy, it is critical to define the individual elements of gustatory organs to understand the principles of gustatory coding. There is a special need to define the components in Drosophila, which has emerged as a leading genetic model system for the study of taste (Montell, 2009).

The legs of Drosophila are gustatory organs. Their tarsi contain taste sensilla that make initial contact with potential food sources. Subsequent contact is made by sensilla on the labellum, a taste organ of the mouthparts. Both taste organs report the presence of sugars, an indication of nutritive value, and bitter compounds, an indication of toxicity. Evaluation of these tastants informs the vital decision as to whether to ingest a food source (Dethier, 1976).

Received Feb. 14, 2014; revised April 14, 2014; accepted April 14, 2014.

Author contributions: F.L., A.D., L.A.W., J.Y.K., and J.R.C. designed research; F.L., A.D., L.A.W., and J.Y.K. performed research; F.L., A.D., L.A.W., J.Y.K., and J.R.C. analyzed data; F.L., A.D., and J.R.C. wrote the paper.

This work was supported by a National Institutes of Health (NIH) National Research Service Award predoctoral grant (F.L.), an NIH training grant, and grants from the NIH (J.R.C.). We thank Zhenting Jiang and Barry Piekos for their assistance with electron microscopy. We thank Frédéric Marion-Poll, Kathy Nagel, and members of the Carlson laboratory for discussion and comments on this manuscript.

The authors declare no competing financial interests.

Correspondence should be addressed to John R. Carlson at the above address. E-mail: john.carlson@yale.edu.

DOI:10.1523/JNEUROSCI.0649-14.2014

Copyright $\odot 2014$ the authors $\quad 0270-6474 / 14 / 347148-17 \$ 15.00 / 0$
The taste sensilla of the Drosophila labellum were analyzed extensively. Most of the $\sim 31$ labellar sensilla contain four gustatory neurons: (1) one responsive to sugars; (2) one to bitter compounds and high salt concentrations; (3) one to low salt concentrations; and (4) another to water or low osmolarity (Hiroi et al., 2004). A panel of 16 bitter tastants was tested against all 31 sensilla and defined five classes of sensilla (Weiss et al., 2011). One class gave no excitatory responses to any bitter compound. The other four classes each contained one bitter-sensing neuron, with a different response profile in each class.

There has been much less analysis of the tarsal sensilla, in part because of technical challenges in recording from them. Electrophysiological recordings from the four most distal tarsal segments of forelegs revealed four kinds of cells, excited by sugars, bitter compounds, water, or low concentrations of salt (Meunier et al., 2000, 2003). Sensilla were not identical: one was excited by berberine but not quinine, two were excited by quinine but not berberine, and others were excited by neither (Meunier et al., 2003). Heterogeneity among sensilla in response to pheromonal or other taste stimuli was also observed in subsequent studies with limited numbers of tarsal sensilla and stimuli, using either electrophysiology (Toda et al., 2012) or $\mathrm{Ca}^{2+}$ imaging (Miyamoto et al., 2013).

Here we examine basic principles of taste coding through a systematic anatomical, electrophysiological, and molecular examination of tarsal sensilla. We provide an anatomical map of the 
A

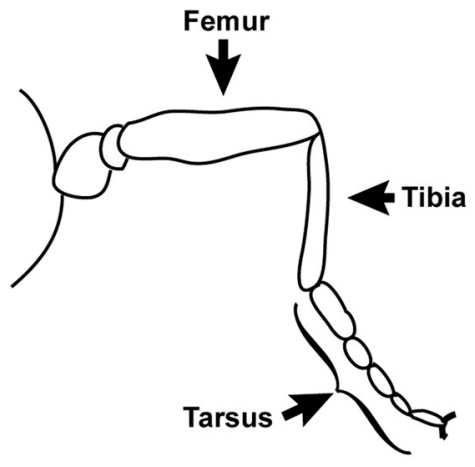

B
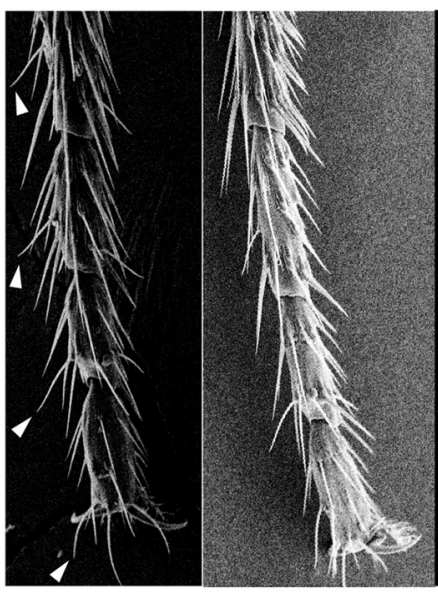

Female

Foreleg

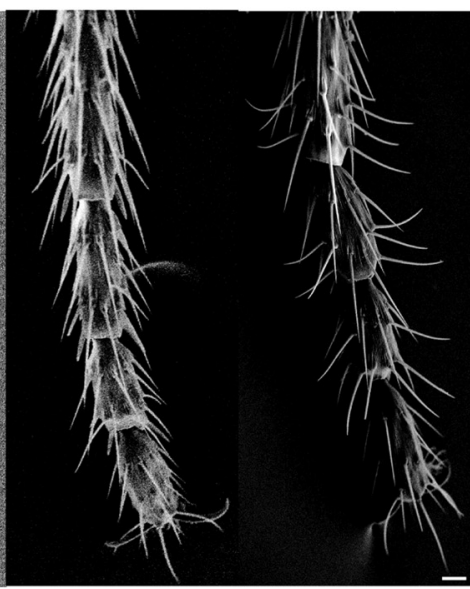

Female Hindleg
Male Foreleg

C

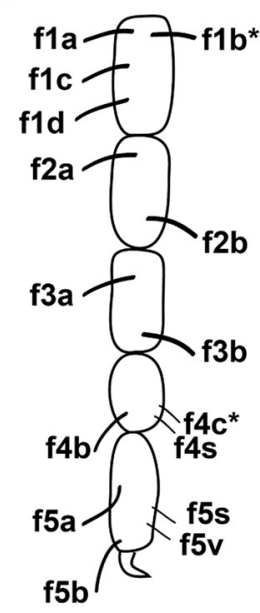

Female Foreleg

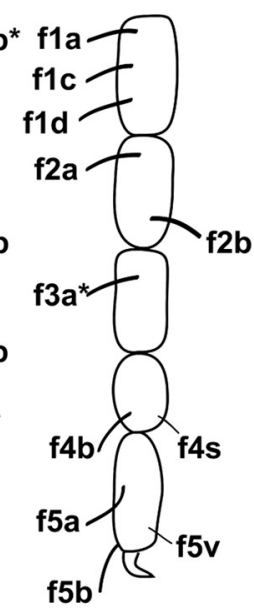

Female Midleg

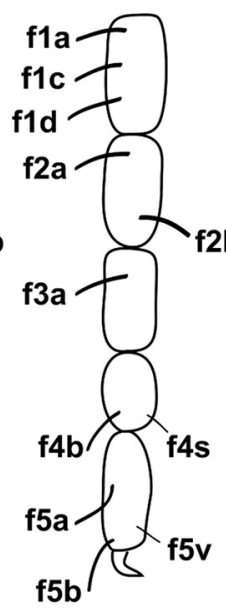

Female Hindleg
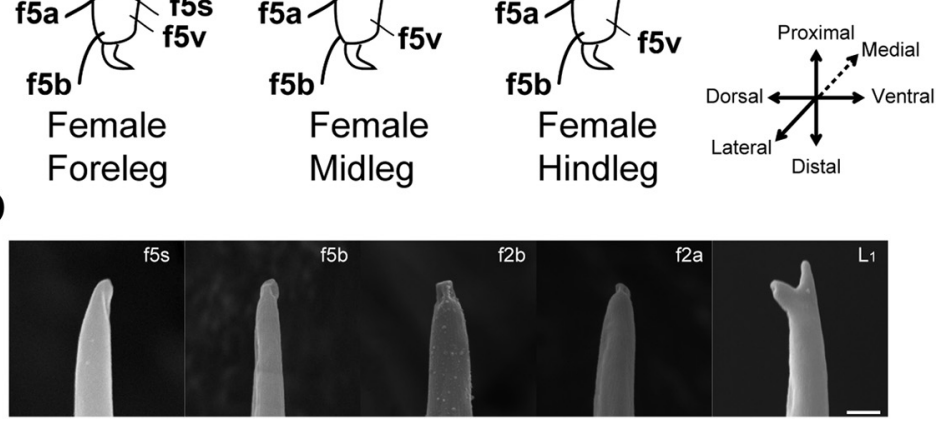

Figure 1. $A$, Drosophila leg. $\boldsymbol{B}$, Scanning electron micrographs of the tarsi. In addition to taste sensilla, other bristles are visible. Arrowheads indicate the f2a, f3a, f4b, and f5b sensilla. Scale bar, $10 \mu \mathrm{m}$. C, Map of tarsal taste sensilla. All sensilla are organized in pairs, except $\mathrm{f} 1 \mathrm{~b}$ and $\mathrm{f} 4 \mathrm{c}$ in the foreleg and $\mathrm{f3a}$ in the midleg, which are marked with an asterisk. The lateral aspect of the leg is shown; most sensilla have a counterpart, extending from the medial side of the leg, which is not visible in the diagram. We note that f4c is small, although not so designated by "s." D, Tips of tarsal sensilla and a labellar sensillum, $\mathrm{L}_{1}$. Scale bar, $10 \mu \mathrm{m}$.

sensilla of all five tarsal segments of female forelegs, midlegs, and hindlegs. We test electrophysiologically 40 tastants against the taste sensilla of the female foreleg. Six functional types of sensilla are defined. The foreleg, midleg, and labellum are functionally distinct, providing different patterns of sensory input with which the fly may evaluate potential food sources. We analyze the expression of all 68 gustatory receptor $(\mathrm{Gr})$ taste receptors and find that $28 \mathrm{Gr}-G A L 4$ drivers are expressed in the legs. The molecular results are integrated with the anatomical and physiological results to generate a receptor-to-neuron map and to elucidate the underlying molecular and cellular bases of taste coding.

\section{Materials and Methods}

Drosophila stocks. Canton-S flies, raised on standard cornmeal agar medium at room temperature $\left(22 \pm 2^{\circ} \mathrm{C}\right)$, were used for electrophysiological recordings at ages 5-7 $\mathrm{d}$ after eclosion. Transgenic flies used for GFP visualization were kept at $25^{\circ} \mathrm{C}$ for 5-10 d after eclosion before experimentation. For visualization of GFP by light microscopy, lines doubly homozygous for the Gr-GAL4 driver and for the UAS- $m C D 8: G F P$ reporter were used except in cases in which the lines were homozygous lethal. The collection of Gr-GAL4 lines was from Weiss et al. (2011), supplemented by additional Gr-GAL4 lines from H. Amrein (Texas A\&M Health Sciences Center, College Station, TX) (Gr28a-GAL4, Gr28b.d-GAL4, Gr59b-GAL4, and Gr68a-GAL4) and K. Scott (UC Berkeley, Berkeley, CA) (Gr21a-GAL4, Gr22cGAL4, Gr28b.e-GAL4). w;UAS-mCD8-GFP was used as a source of GFP reporter, and Gr66a-RFP was from Dahanukar et al. (2007).

Tastants. Tastants were dissolved in $30 \mathrm{~mm}$ tricholine citrate (TCC; Sigma-Aldrich), which inhibits the activity of the water cell (Wieczorek and Wolff, 1989). Tastants of the highest purity available were obtained from SigmaAldrich. All tastants were stored at $-20^{\circ} \mathrm{C}$, and aliquots were kept at $4^{\circ} \mathrm{C}$ and discarded after 1 week of use. Sugars were tested at $100 \mathrm{~mm}$ concentrations, and amino acids were tested at 25 $\mathrm{mm}$. Other tastants were tested at the following concentrations unless otherwise indicated: aristolochic acid, $1 \mathrm{~mm}$; berberine chloride, 1 $\mathrm{mm}$; caffeine, $10 \mathrm{~mm}$; coumarin, $10 \mathrm{~mm}$; $N$-diethyl- $m$-toluamide (DEET), $10 \mathrm{~mm}$; denatonium benzoate, $10 \mathrm{~mm}$; escin, $10 \mathrm{~mm}$; gossypol, $1 \mathrm{~mm}$; lobeline hydrochloride, $1 \mathrm{~mm}$; saponin from quaillaja bark, $1 \%$; sucrose ocataacetate, $1 \mathrm{~mm}$; sparteine sulfate salt, $10 \mathrm{~mm}$; strychnine nitrate salt, $10 \mathrm{~mm}$; theophylline, $10 \mathrm{~mm}$; gibberellic acid, $10 \mathrm{~mm}$; (-)-catechin, 1 $\mathrm{mm}$; cucurbitacin hydrate, $1 \mathrm{~mm}$; atropine, 1 $\mathrm{mm}$; harmaline, $1 \mathrm{~mm}$; (-)-nicotine, $1 \%$; sinigrin hydrate, $10 \mathrm{~mm}$; theobromine, $10 \mathrm{~mm}$; naringen, $1 \mathrm{~mm}$; amygdalin, $1 \mathrm{~mm}$; salicin, $10 \mathrm{~mm}$; and allyl isothiocyanate (AITC), $2 \%$.

Electron microscopy. Legs from 5-d-old flies were dissected and rinsed in increasing con- 
centrations of ethanol (10,30,50, and $100 \%)$ over $2 \mathrm{~h}$ and were incubated in $100 \%$ ethanol overnight. Samples were then dehydrated with critical point drying using liquid carbon dioxide before being sputter-coated with gold or platinum. At least two sensilla of each kind (e.g., fla) were observed.

Electrophysiology. Electrophysiological recordings were performed with the tip-recording method (Hodgson et al., 1955), with minor modifications. All electrophysiological testing was of female Canton-S flies 5-7 d after eclosion. Flies were transferred to fresh food shortly after eclosion and tested 5-7 d later. Flies were decapitated 1-2 h before recordings. For recording, the flies were secured with insect pins and double-sided tape on a microscope slide coated with Sylgard (Dow Corning). Briefly, a reference electrode containing Ringer's solution was inserted into the body of the fly. The recording electrode consists of a fine glass pipette (10-15 $\mu \mathrm{m}$ tip diameter) and connects to an amplifier with a silver wire. This pipette performs the dual function of recording electrode and container for the stimulus. Recording starts the moment the glass capillary electrode contacts the tip of the sensillum. Neuronal firing frequencies were calculated by counting the number of action potentials elicited from 200 to $700 \mathrm{~ms}$ after initial contact, as in previous studies (Dahanukar et al., 2001, 2007; Weiss et al., 2011). Traces were recorded using TasteProbe (Syntech) and analyzed with Autospike 3.1 (Syntech).

To avoid the effect of desensitization, stimuli were given at least $3 \mathrm{~min}$ apart. Also, as a precaution, each fly was tested periodically with $100 \mathrm{~mm}$ sucrose. Recording was continued from the fly only if a normal response to this strong stimulus was measured.

Statistical analysis. Hierarchical cluster analyses were performed using Ward's method with PAST (paleontological statistics software package for education and data analysis; Hammer et al., 2001). This technique organizes the data into clusters based on the response profiles of each sensillum to the panel of tastants. Euclidean distances were calculated according to Ward's classification method for the hierarchical cluster analysis. All error bars are SEM. Molecular descriptors were calculated by Dragon (http://www.talete.mi.it). Descriptors were normalized for principal component analysis.

\section{Results}

\section{Anatomical organization of tarsal taste sensilla}

We examined legs on females of our laboratory Canton-S strain of Drosophila for the presence of taste sensilla, using both light and scanning electron microscopy (Fig. 1A,B). On the tarsal segments of the foreleg, midleg, and hindleg, we observed $\sim 28,21$, and 22 sensilla, respectively, with morphology expected of taste sensilla.

We constructed a map of these sensilla (Fig. 1C) using a nomenclature used in previous studies of insect taste organs (Meunier et al., 2000, 2003; Zhang et al., 2010, 2011). Each sensillum is designated according to sex ( $m$ or $\mathrm{f}$ ), tarsal segment ( 1 to 5 , with 1 the most proximal), and identity within each segment (a to d, with "a" the most proximal; s to designate small sensilla; $v$ to designate a sensillum named by Miyamoto et al., 2013). Most sensilla are organized in symmetric pairs, with lateral sensilla having symmetric counterparts on the medial side of the leg; the few exceptions to this symmetry rule are indicated by asterisks in Figure $1 C$. The organization of the tarsal sensilla was stereotyped, with $<10 \%$ of flies deviating from the consensus pattern among 50 flies examined.

Our map agrees reasonably well with one that was established previously for the four most distal segments of the Drosophila female foreleg (Meunier et al., 2000); an exception is that, in our laboratory strain, we observed one additional sensillum that we designate $\mathrm{f} 4 \mathrm{c}$, and we added the f5v sensillum identified by Miyamoto et al. (2013) (Fig. 1C). We also extended previous work in two other ways. First, we mapped the first tarsal segment of the foreleg. This most proximal segment contains four sensilla, three on the dorsal side of the segment and one in a more ventral position. Second, we constructed maps of the midleg and hindleg, as well as the foreleg (Fig. 1C).
Table 1. Compounds tested

\begin{tabular}{|c|c|c|}
\hline Tastant & $\begin{array}{l}\text { Human taste } \\
\text { perception }\end{array}$ & Source/remarks \\
\hline \multicolumn{3}{|l|}{ Monosaccharides } \\
\hline d-Fructose (100 mm) & Sweet & Honey, fruits \\
\hline $\mathrm{d}$-Glucose (100 mм) & Sweet & Most common sugar \\
\hline $\mathrm{d}$-Xylose (100 mм) & Sweet & Corn cobs, pecan shells, cottonseed hulls \\
\hline \multicolumn{3}{|l|}{ Disaccharides } \\
\hline d-Maltose (100 mм) & Sweet & Malt sugar \\
\hline d-Sucrose (100 mм) & Sweet & Principal sugar in fruits and vegetables \\
\hline Trehalose (100 mм) & Sweet & Fungi, moulds, algae, yeast \\
\hline Palatinose (100 mm) & Sweet & Honey, sugar cane \\
\hline \multicolumn{3}{|l|}{ Trisaccharides } \\
\hline Maltotriose (100 mM) & Sweet & Corn syrup; amylolyosis product of starch \\
\hline \multicolumn{3}{|l|}{ Alkaloids } \\
\hline Atropine (1 mм) & Bitter & $\begin{array}{l}\text { Deadly nightshade, Jimson weed, } \\
\text { Tailflower }\end{array}$ \\
\hline Berberine (1 mM) & Bitter & $\begin{array}{l}\text { Golden seal, bayberry, Oregon grape } \\
\text { and goldthread }\end{array}$ \\
\hline Caffeine (10 mм) & Bitter & Coffee, chocolate, tea, kola nut \\
\hline Harmaline (1 mм) & Bitter & Jungle vine, Syrian rue \\
\hline Lobeline (1 mm) & Bitter & Indian tobacco, Cardinal flower \\
\hline Nicotine (1\%) & Bitter & Tobacco, nightshades \\
\hline Quinine (1 mм) & Bitter & Cinchona tree bark \\
\hline Sparteine (10 mm) & Bitter & Scotch broom \\
\hline Strychnine (1 mм) & Bitter & Strychnos seeds \\
\hline Theobromide (1 mM) & Bitter & Cacao, tea, kola nut, chocolate \\
\hline Theophylline (10 mm) & Bitter & Tea leaves \\
\hline \multicolumn{3}{|l|}{ Phenanthrene } \\
\hline Aristolochic acid (1 mм) & Bitter & Aristolochia family of plants \\
\hline \multicolumn{3}{|l|}{ Terpenoids } \\
\hline Azadirachtin (1 mм) & Bitter & Neem tree \\
\hline Escin $(10 \mathrm{~mm})$ & Bitter & Horse chestnut tree \\
\hline Gossypol (1 mм) & Bitter & Cotton \\
\hline Saponin (1\%) & Bitter & Soapbark tree \\
\hline \multicolumn{3}{|l|}{ Terpene } \\
\hline Gibberellic acid (1 mm) & Bitter & Plant growth hormone \\
\hline \multicolumn{3}{|l|}{ Benzopyrone } \\
\hline Coumarin $(10 \mathrm{~mm})$ & Bitter & Tonka bean, honey clover \\
\hline \multicolumn{3}{|l|}{ Phenol } \\
\hline Catechin (1 mm) & Bitter & Spotted knapweed, cacao beans \\
\hline \multicolumn{3}{|l|}{ Glycosides } \\
\hline Amygdalin (1 mм) & Bitter & Fruit seeds \\
\hline Cucurbitacin (1 mM) & Bitter & Pumpkins, gourds \\
\hline Naringen (1 mM) & Bitter & Grapefruit \\
\hline Salicin (1 mM) & Bitter & Poplar and willow bark \\
\hline Sinigrin (1 mM) & Bitter & Brussel sprouts, broccoli, black mustard \\
\hline Allyl isothiocyanate (2 mM) & Pungent & Mustard, horseradish, wasabi \\
\hline \multicolumn{3}{|l|}{ Amino acids } \\
\hline I-Alanine (50 mм) & Sweet & Nonpolar \\
\hline I-Histidine ( $50 \mathrm{~mm})$ & Bitter & Charged side chain \\
\hline I-Asparagine $(50 \mathrm{~mm})$ & Sour & Uncharged with polar side chain \\
\hline \multicolumn{3}{|l|}{ Synthetic } \\
\hline Denatonium (10 mm) & Bitter & Most bitter compound known to man \\
\hline Sucrose octaacetate (1 mM) & Bitter & $\begin{array}{l}\text { Inert ingredient in herbicides and } \\
\text { pesticides }\end{array}$ \\
\hline DEET (10 mm) & Bitter & Insect repellent \\
\hline
\end{tabular}

The organization of the taste sensilla was similar on all three legs, with two exceptions. The f1b, f3b, f4c, and f5s sensilla were found only on the foreleg, and $\mathrm{f} 3 \mathrm{a}$ was unpaired only on the midleg.

An additional 10-12 presumptive taste sensilla were observed on the tibia of each leg. The tibia appeared more variable in both number and location of sensilla, but this apparent variability could be attributable in part to the presence of a dense population 


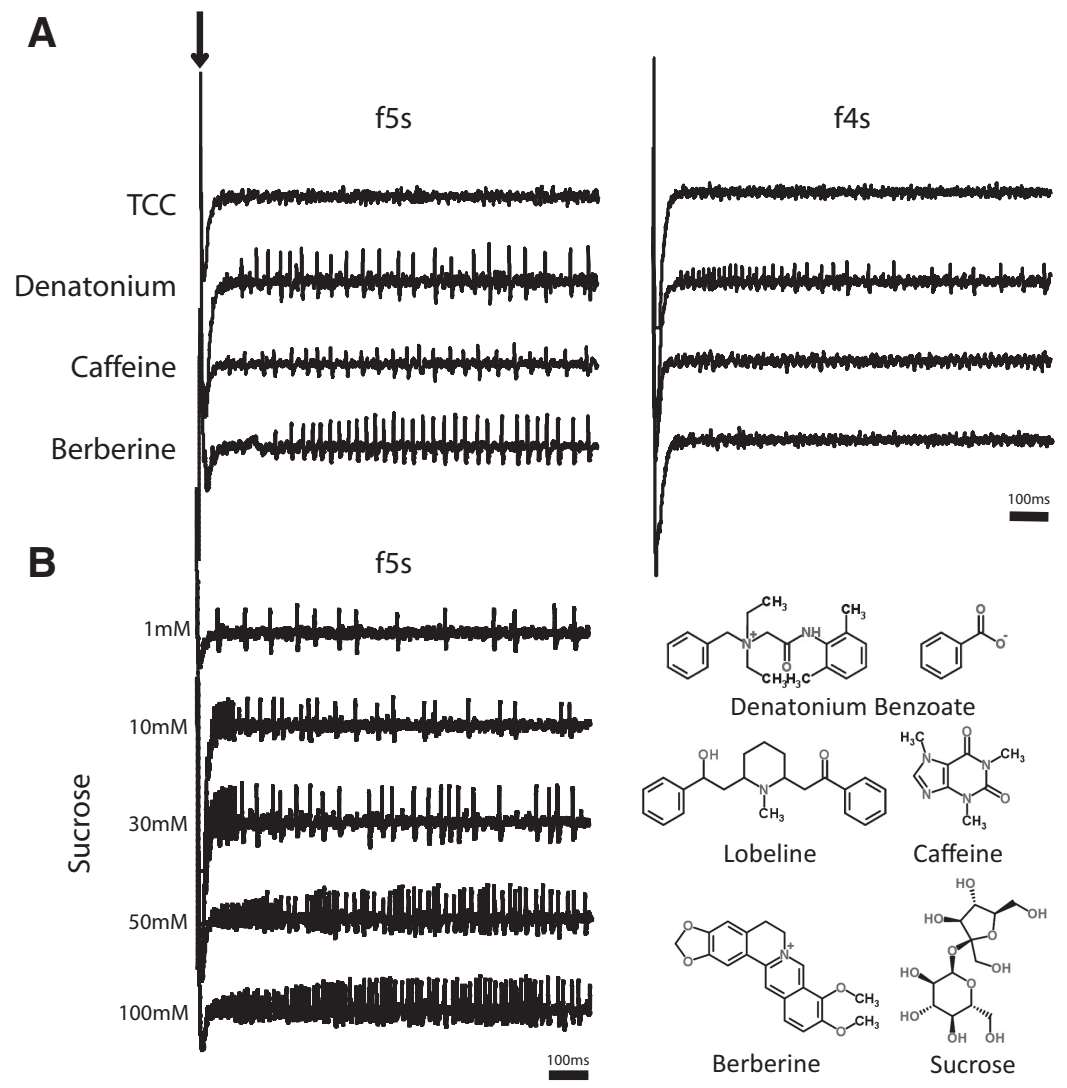

Figure 2. Sample traces from Canton-S flies. Arrow indicates the contact artifact observed at the beginning of each trace. TCC was tested at a $30 \mathrm{~mm}$ concentration, berberine was tested at $1 \mathrm{~mm}$, and denatonium and caffeine were tested at $10 \mathrm{~mm}$.

of thick, long spines that often obstructed the view of taste sensilla. We focused the rest of our analysis on tarsal sensilla because of their anatomical consistency, ease of viewing, and accessibility to physiological recording.

We also examined male legs (Fig. $1 B$, right). Male forelegs contain more taste sensilla than their female counterparts (Nayak and Singh, 1983), and many of them are asymmetric. On account of the relative simplicity of female forelegs, we focused our analysis on females. Male midlegs and hindlegs appeared similar to their female counterparts.

Taste sensilla on the labellum contain two morphological classes of tips: forked and straight (Falk et al., 1976). We examined the morphology of the tarsal taste sensilla by scanning electron microscopy at $8000-20,000 \times$ magnification. At least two sensilla of each kind (e.g., fla) were examined. All the female foreleg tarsal sensilla examined ( $n=53$ tips) contained straight tips (Fig. 1D; tips of four tarsal sensilla and one forked labellar sensillum, $\mathrm{L}_{1}$, are shown). Likewise, only straight tips were observed in more limited analysis of the midleg $(n=16)$ and hindleg $(n=4)$ of females and the foreleg of males $(n=9)$.

Systematic analysis of taste responses in the foreleg

We systematically measured the electrophysiological responses of female tarsal sensilla, initially on the foreleg, to a panel of tastants. The foreleg was chosen because it has been the subject of previous behavioral studies in a variety of insects (Ma and Schoonhoven, 1973; Du et al., 1995; Ozaki et al., 2011; Ryuda et al., 2013) and because recording from the other legs is more technically challenging. The female foreleg was chosen because its sensillar organization is simpler than that of the male foreleg. We examined all tarsal sensilla on the foreleg as detailed below, including both lateral and medial sensilla of each pair, except that we did not analyze $\mathrm{flb}$, which was difficult to access because of the angle at which it projects; $\mathrm{f} 5 \mathrm{v}$ and $\mathrm{f} 4 \mathrm{c}$ pose major challenges because of limited accessibility but are considered below.

We tested a panel of 40 compounds, chosen for their chemical diversity and their ecological or behavioral significance to Drosophila or other insects (Table 1). The panel includes sugar compounds, including monosaccharides, disaccharides, and oligosaccharides, bitter compounds, such as alkaloids and glycosides, amino acids, and allyl-isothiocyanate, a pungent compound found in wasabi. Most of these compounds have not been tested previously with leg sensilla. Sugars were tested at $100 \mathrm{~mm}$ concentrations; concentrations of bitter compounds depended on their solubility and in most cases were tested at $1 \mathrm{~mm}$ concentrations. These concentrations were also chosen to allow comparison with previous studies of labellar sensilla (Dahanukar et al., 2007; Weiss et al., 2011) and in many cases because of their behavioral significance.

We used single-unit electrophysiology to measure the response elicited by each member of the panel. Because contact artifacts are often observed when the electrode contacts the sensillum, we quantified responses by counting the number of action potentials generated from 200 to $700 \mathrm{~ms}$ after contact, as in previous studies (Dahanukar et al., 2001, 2007; Weiss et al., 2011) rather than during the period immediately after contact.

As in previous studies (Dahanukar et al., 2001, 2007; Weiss et al., 2011), tastants were dissolved in $30 \mathrm{~mm}$ TCC to suppress activity of the water-sensing neuron and to thereby produce recordings with less background firing arising from the water neuron (Wieczorek and Wolff, 1989). Recordings from tarsal sensilla with TCC alone revealed very low activity, approaching 0 spikes/s in many cases.

We initially tested all 40 compounds of the panel against the 24 more accessible taste sensilla, constituting 12 symmetric pairs, on the female foreleg tarsi. Most recordings were performed on either the lateral side of the right leg or the medial side of the left leg. No difference was observed between these sensillar counterparts, and therefore we pooled the data and report the results for the 12 pairs of sensilla without regard to their lateral versus medial location or location on the right versus left leg.

On account of the unprecedented number of sensillum-tastant combinations tested in this study $(n=480)$, we implemented a strategy to maximize economy of experimentation. We initially tested the responses of all tastants in each of these 12 pairs of sensilla three times, distributed across multiple flies, in most cases three. If there was little or no response, defined as a mean response of $<5$ spikes/s, from a particular kind of sensillum, no additional tests were conducted. If the mean response was $\geq 5$ spikes/s, the compound was tested at least seven times, with these 
recordings taken from at least three flies. We note that 5 spikes/s is $>2$ SDs above the background firing rate in most sensilla. Efforts were made to avoid desensitization during testing and to ensure that recordings were taken only from healthy flies (see Materials and Methods).

\section{A functional map of the female foreleg tarsal taste sensilla}

We first confirmed results of a previous study (Meunier et al., 2003) that f4s and f5s both respond to the bitter compound denatonium but differ in their sensitivity to berberine and caffeine, which elicit responses from $\mathrm{f} 5 \mathrm{~s}$ but not $\mathrm{f} 4 \mathrm{~s}$ at the tested concentration (Fig. 2A). We also confirmed the response of the f5s sensillum to sucrose (Meunier et al., 2000; Fig. 2B).

We then tested physiological responses of $480(40 \times 12)$ tastant-sensillum combinations (Fig. 3, Table 2). The response matrix shows that different sensilla respond to distinct subsets of tastants, and different tastants elicit responses from distinct subsets of sensilla. The greatest mean responses observed were those elicited by $100 \mathrm{~mm}$ sucrose from f5s, f5b, and $\mathrm{f} 4 \mathrm{~s}$, which were $\sim 50$ spikes/s. All tested sugars evoked responses of $\geq 10$ spikes/s from at least one sensillum, with the exception of xylose, which elicited little or no response from any sensilla. Of the 40 tested tastants, 27 were bitter compounds, and most of them elicited a mean response $>5$ spikes/s from at least one sensillum; only seven elicited little or no response from any sensilla. The greatest responses to bitter compounds were those elicited by sparteine and aristolochic acid from f5s, which were $49 \pm 2$ and $41 \pm 4$ spikes/s, respectively. Two of the tested amino acids elicited weak responses from one sensillum, $\mathrm{f} 5 \mathrm{~s}$ in both cases.

The tarsal sensilla differed markedly in their tuning breadths (Fig. 4). One sensillum, f5s, responded to more tastants than any other: it gave responses of $\geq 5$ spikes/s to 28 of the 40 compounds tested, including both sugars and bitter compounds. $44 \mathrm{~s}$ and $\mathrm{f} 5 \mathrm{~b}$ had narrower response profiles, giving mean responses of $\geq 5$ spikes/s to 16 tastants. $\mathrm{f3b}, \mathrm{f} 2 \mathrm{~b}$, and $\mathrm{f} 4 \mathrm{~b}$ had still narrower spectra: they gave such responses to five, five, and four tastants, respectively, all sugars. The other sensilla gave no such responses to any tested compounds.

To determine how many functional types of sensilla could be distinguished from the analysis of these 12 sensilla with the panel of 40 tastants, we performed a hierarchical clustering analysis. The analysis revealed four functional types (Fig. 5A), designated A1, A2, B, and C. Type A1 consists of a single member, f5s, the most broadly f5s f5b f5a f4s f4b f3b f3a f2b f2a f1d f1c f1a

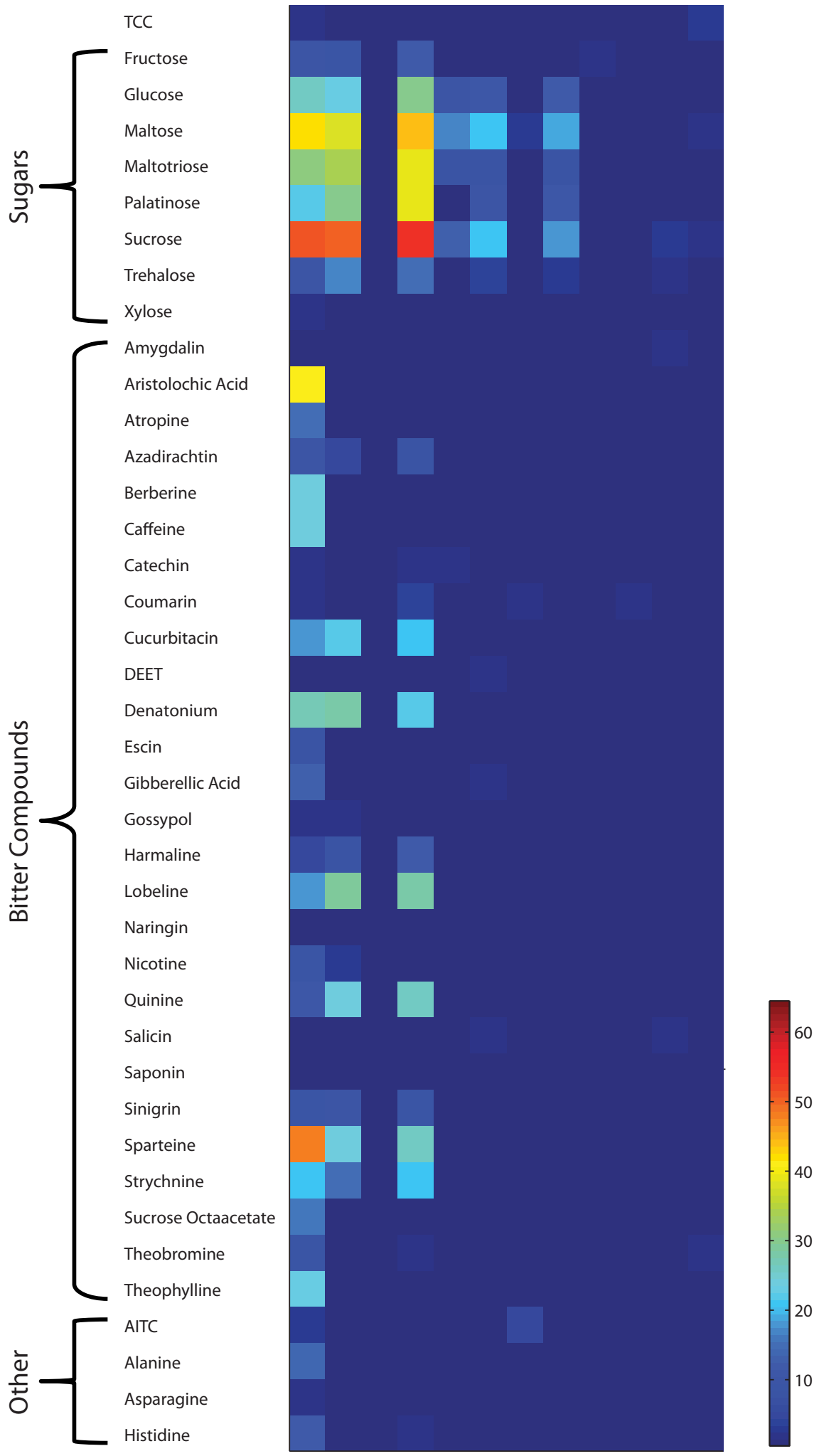

Figure 3. Response profiles of 12 pairs of foreleg sensilla. The heat map shows the electrophysiological responses of 12 female foreleg tarsal sensilla to a panel of 40 compounds. Control responses to the TCC were not subtracted. Values represent the mean responses in spikes per second. For each value, $n \geq 7$ for responses $\geq 5$ spikes $/ s$; otherwise, $n \geq 3$. Numerical data are provided in Table 2 .

tuned sensillum. Type A2 consists of $\mathrm{f} 4 \mathrm{~s}$ and $\mathrm{f} 5 \mathrm{~b}$, whose sugar responses are similar to those of $\mathrm{A} 1$ but that respond to fewer bitter compounds (Fig. 5B). Type B includes f4b, f3b, and f $2 \mathrm{~b}$, which show lower responses to sugars than types A1 or A2 and 
Table 2. Response profiles of 12 pairs of foreleg sensilla

\begin{tabular}{|c|c|c|c|c|c|c|c|c|c|c|c|c|}
\hline & f5s & $f 5 b$ & f5a & f4s & $f 4 b$ & $f 3 b$ & f3a & $f 2 b$ & $f 2 a$ & f1d & fic & f1a \\
\hline $\mathrm{TCC}$ & $2.8 \pm 0.6$ & \pm 0.4 & \pm 0.2 & $1 \pm 0.1$ & $0.0 \pm 0.0$ & $0.2 \pm 0.2$ & $2 \pm 0.9$ & $0 \pm 0.0$ & $1.9 \pm 1.4$ & $.8 \pm 1.2$ & $9 \pm 1.0$ & $2 \pm 2.3$ \\
\hline Fructose & $10.8 \pm 1.8$ & $9.2 \pm 1.1$ & $0.5 \pm 0.5$ & $12.3 \pm 2.2$ & $1.8 \pm 0.6$ & $0.5 \pm 0.5$ & $.4 \pm 0.4$ & $0.5 \pm 0.3$ & $2.0 \pm 1.1$ & $0.3 \pm 0.3$ & $0.0 \pm 0.0$ & $0.0 \pm 0.0$ \\
\hline Glucose & $26.5 \pm 3.7$ & $23.5 \pm 2.5$ & $0.0 \pm 0.0$ & $30.8 \pm 2.9$ & $10.4 \pm 1.9$ & $11.4 \pm 1.1$ & $0.0 \pm 0.0$ & $12.2 \pm 4.1$ & $1.7 \pm 1.7$ & $0.0 \pm 0.0$ & $0.0 \pm 0.0$ & $0.8 \pm 0.8$ \\
\hline Maltotriose & $31.6 \pm 3.4$ & $34.3 \pm 4.4$ & $0.0 \pm 0.0$ & $39.7 \pm 6.6$ & $8.7 \pm 4.0$ & $8.2 \pm 2.2$ & $0.0 \pm 0.0$ & $8.7 \pm 1.7$ & $1.0 \pm 1.0$ & $0.0 \pm 0.0$ & $0.7 \pm 0.7$ & $0.7 \pm 0.7$ \\
\hline Palatinose & $22.7 \pm 1.0$ & $30.0 \pm 4.8$ & $0.0 \pm 0.0$ & $39.0 \pm 2.6$ & $1.3 \pm 1.0$ & $10.8 \pm 2.2$ & $0.0 \pm 0.0$ & $11.3 \pm 0.9$ & $0.0 \pm 0.0$ & $0.0 \pm 0.0$ & $0.7 \pm 0.7$ & $0.0 \pm 0.0$ \\
\hline Sucrose & $51.7 \pm 3.0$ & $50.2 \pm 4.4$ & $0.3 \pm 0.3$ & $54.5 \pm 3.2$ & $13.9 \pm 3.7$ & $21.4 \pm 2.6$ & $0.0 \pm 0.0$ & $18.7 \pm 2.2$ & $0.0 \pm 0.0$ & $1.0 \pm$ & $3.0 \pm 1.7$ & $2.7 \pm 2.7$ \\
\hline Amygdalin & $0.8 \pm 0.8$ & $0.0 \pm 0.0$ & $0.0 \pm 0.0$ & $0.0 \pm 0.0$ & $0.0 \pm 0.0$ & $0.0 \pm 0.0$ & $0.0 \pm 0.0$ & $0.0 \pm 0.0$ & $0.0 \pm 0.0$ & $0.0 \pm 0.0$ & $2.7 \pm 2.7$ & $0.0 \pm 0.0$ \\
\hline Aristolochic acid & $41.4 \pm 3.7$ & $0.0 \pm 0.0$ & $0.0 \pm 0.0$ & $0.0 \pm 0.0$ & $0.0 \pm 0.0$ & $1.3 \pm 1.3$ & $0.5 \pm 0.5$ & $0.0 \pm 0.0$ & $0.0 \pm 0.0$ & $0.0 \pm 0.0$ & $0.5 \pm 0.5$ & $0.0 \pm 0.0$ \\
\hline Atropine & $15.2 \pm 2.2$ & $0.0 \pm 0.0$ & $0.0 \pm 0.0$ & $0.0 \pm 0.0$ & $0.7 \pm 0.7$ & $0.0 \pm$ & $0.0 \pm 0.0$ & $0.0 \pm 0.0$ & $0.0 \pm$ & $0.7 \pm 0.7$ & $0.0 \pm$ & $0.0 \pm 0.0$ \\
\hline htin & $3 \pm 1.9$ & $5.2 \pm 2.2$ & $0.0 \pm$ & $8.4 \pm$ & $0.0 \pm$ & $0.0 \pm$ & $0.0 \pm$ & $0.0 \pm$ & $0.0 \pm$ & $0.7=$ & $0.7=$ & $0.0 \pm 0.0$ \\
\hline & $4 \pm 4.1$ & $0.0 \pm$ & $0.0 \pm$ & $0.0 \pm$ & $0.0 \pm$ & $0.0 \pm$ & $0.0 \pm$ & $0.0 \pm$ & $0.0 \pm$ & $0=$ & $0.0 \pm$ & $0 \pm 0.0$ \\
\hline Caffeine & $24.9 \pm 2.0$ & $0.0 \pm$ & $1.3 \pm$ & $0.2 \pm$ & 0.0 & $0.0 \pm$ & $0.0 \pm 0.0$ & $0.0 \pm$ & $0.0 \pm$ & $0.0 \pm$ & $0.0 \pm$ & $.0 \pm 0.0$ \\
\hline atonium & $3 \pm 1.4$ & $28.3 \pm 3.6$ & $0.4 \pm$ & $22.5 \pm 1.3$ & $0=$ & $0.8 \pm$ & $0.0 \pm$ & $0.0 \pm$ & $0.7=$ & $0.0 \pm$ & $0.0 \pm$ & $0.7 \pm 0.7$ \\
\hline Escin & $4 \pm 0.9$ & $0.0 \pm 0.0$ & $0.0 \pm$ & $00+$ & $n+$ & $0.0 \pm$ & $0.7 \pm 0.7$ & $0.0 \pm$ & $0.7=$ & $0.0 \pm$ & $0.0 \pm$ & $0.0 \pm 0.0$ \\
\hline Gibberellic acid & $13.1 \pm 2.4$ & $0.0 \pm 0.0$ & $0.0 \pm$ & $1.4 \pm$ & & & $0.0 \pm 0.0$ & $0.0 \pm$ & $0.7=$ & $1.3=$ & $0.7=$ & $1.3 \pm 0.7$ \\
\hline Gossypol & $2.3 \pm 1.0$ & $2.7 \pm 2.7$ & $0.0 \pm 0.0$ & $0.0 \pm 0.0$ & & $1.3 \pm$ & $1.3 \pm 0.7$ & $0.7 \pm$ & $0.0 \pm$ & $0.0 \pm$ & $0.0 \pm$ & $1.3 \pm 0.7$ \\
\hline Harmaline & $5.6 \pm 1.4$ & $8.8 \pm 2.3$ & $0.0 \pm 0.0$ & $12.4 \pm 2.1$ & $0.0 \pm$ & $0.0 \pm 0.0$ & $0.0 \pm 0.0$ & $0.7 \pm$ & $0.0 \pm 0.0$ & $0.0 \pm$ & $0.0 \pm$ & $0.0 \pm 0.0$ \\
\hline Lobeline & $18.1 \pm 1.9$ & $29.4 \pm 2.6$ & $0.0 \pm 0.0$ & $28.2 \pm$ & $0.0 \pm$ & $0.0 \pm$ & $0.0 \pm$ & $1.5 \pm$ & $0.0 \pm$ & $0.0 \pm$ & $0.0 \pm$ & $0.0 \pm 0.0$ \\
\hline Naringin & $1.6 \pm 0.9$ & $0.0 \pm 0.0$ & $0.0 \pm 0.0$ & $0.0 \pm$ & $0.0 \pm$ & $0.0 \pm$ & $0.0 \pm 0.0$ & $0.0 \pm$ & $1.3 \pm$ & $0.0 \pm$ & $0.0 \pm$ & $0.0 \pm 0.0$ \\
\hline Nicotine & $9.4 \pm 1.5$ & $3.4 \pm 1.8$ & $0.0 \pm 0.0$ & .0 & $0.0 \pm$ & $0.0 \pm$ & $0.7 \pm 0.7$ & $1.0 \pm$ & $0.0=$ & $0.0=$ & $0.0=$ & $0.7 \pm 0.7$ \\
\hline Quinine & $11.1 \pm 0.9$ & $24.6 \pm 2.0$ & $0.3 \pm 0.3$ & $26.5 \pm 2.2$ & & $0.4 \pm 0.4$ & $0.0 \pm 0.0$ & $0.0 \pm$ & $0.0 \pm 0.0$ & $0.0 \pm$ & $1.3 \pm$ & $0.7 \pm 0.7$ \\
\hline Salicin & $0.0 \pm 0.0$ & $0.0 \pm 0.0$ & $0.0 \pm 0.0$ & $0.0 \pm 0.0$ & $0.0 \pm 0.0$ & $2.0 \pm 2.0$ & $0.7 \pm 0.7$ & $0.7 \pm 0.7$ & $0.0 \pm 0.0$ & $0.0 \pm 0.0$ & $2.7 \pm 2.7$ & $0.0 \pm 0.0$ \\
\hline Saponin & $0.0 \pm 0.0$ & $0.0 \pm 0.0$ & $0.7 \pm 0.7$ & $0.7 \pm 0.7$ & $0.0 \pm 0.0$ & $0.7 \pm 0.7$ & $0.0 \pm 0.0$ & $0.0 \pm 0.0$ & $0.7 \pm 0.7$ & $0.0 \pm 0.0$ & $0.0 \pm 0.0$ & $0.0 \pm 0.0$ \\
\hline Dirin & $9.3 \pm 1.5$ & $.5 \pm 1.4$ & $0.0 \pm 0.0$ & $9.0 \pm 1.9$ & $15+$ & $0.0 \pm 0.0$ & $0.7 \pm 0.7$ & $0.7 \pm$ & $0.0 \pm 0.0$ & $0.7 \pm$ & $0.0 \pm$ & $0.7 \pm 0.7$ \\
\hline Histidine & $12.5 \pm 1.4$ & $1.1 \pm 0.9$ & $0.0 \pm 0.0$ & $2.2 \pm 0.8$ & $0.0 \pm 0.0$ & $0.0 \pm 0.0$ & $0.0 \pm 0.0$ & $0.0 \pm 0.0$ & $1.5 \pm 1.0$ & $0.7 \pm 0.7$ & $0.0 \pm 0.0$ & $0.0 \pm 0.0$ \\
\hline
\end{tabular}

Values represent the mean \pm SEM number of spikes per second. For each value, $n \geq 7$ if responses are $\geq 5$ spikes $/ \mathrm{s} ;$ otherwise, $n \geq 3$. Sensilla $\mathrm{f} 4 \mathrm{c}$ and f1b were not included in the analysis because of their inaccessibility. Control responses to TCC were not subtracted.

which show little if any response to bitter compounds. Type $\mathrm{C}$ showed little if any response to any tested compound. The identification of four types, based on analysis of 480 tastant-sensillum combinations, is consistent with previous studies of more limited scope (Meunier et al., 2000, 2003).

The distribution of these types on the female foreleg is shown in Figure $5 C$. There is a correlation between sensillar tuning breadth and location. The more broadly tuned A1 and A2 sensilla are located closer to the distal tip of the leg. Thus, more broadly tuned sensilla are more likely to come directly in contact with potential food sources. Most C sensilla are located in the more proximal tarsal segments and in the dorsal side of the leg, where they likely have less direct contact with potential food sources.

\section{Tarsal responses differ from labellar responses}

Many of the compounds tested against tarsal sensilla in this study were tested previously against labellar sensilla (Dahanukar et al., 2007; Weiss et al., 2011). Moreover, the present analysis of tarsal sensilla was performed with the same laboratory strain, under similar experimental conditions, and using similar means of eval- uating response as two previous studies of labellar sensilla, providing an unusual opportunity for comparison.

One simple parameter is the maximum response elicited by each tastant in each organ. Of the 27 bitter compounds tested against the foreleg in this study, 15 were tested systematically against all labellar sensilla. Some bitter compounds, such as sparteine, elicited strong responses from at least one sensillum in the foreleg and one in the labellum (Fig. 6). Aristolochic acid elicits a much stronger response from a foreleg sensillum (f5s) than from any labellar sensillum (13 spikes/s maximum, from $\mathrm{S}_{3}$ ). In contrast, saponin elicits one of the strongest labellar responses ( 52 spikes/s from the labellar sensillum $\mathrm{S}_{5}$ ) but essentially no response from any tarsal sensillum tested. A few of the bitter compounds, including cucurbitacin and atropine, elicited $>10$ spikes/s in the foreleg but not in the labellum, although we note that these compounds were tested to a limited extent in the labellum (Weiss et al., 2011).

Another way of comparing taste representations is to construct for each organ an $n$-dimensional taste space in which each dimen- 
f5s (A1)

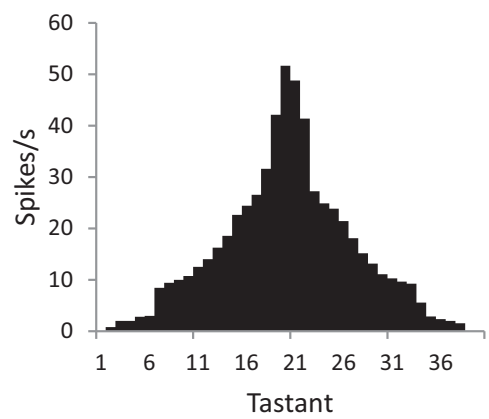

f3b (B)

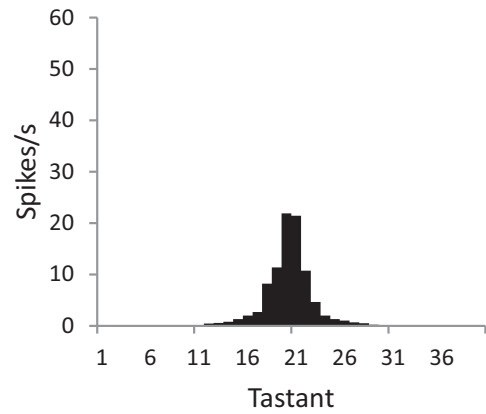

f3a (C)

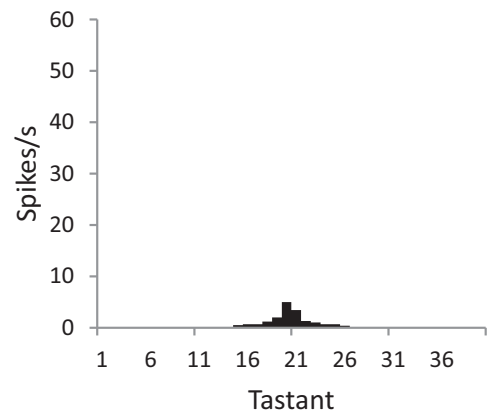

f1c (C)

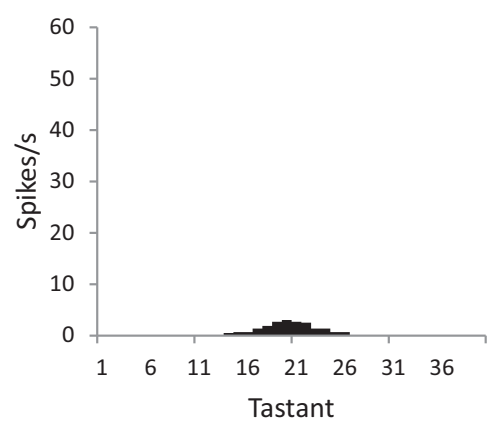

f5b (A2)

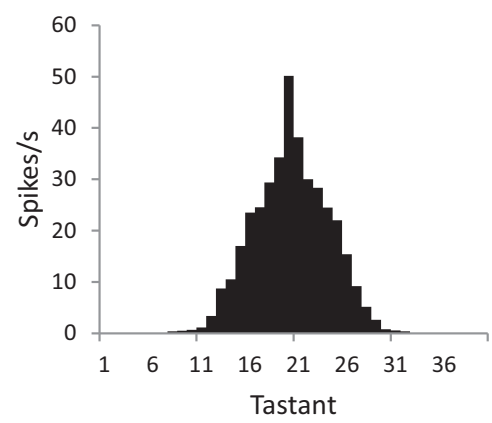

f2b (B)

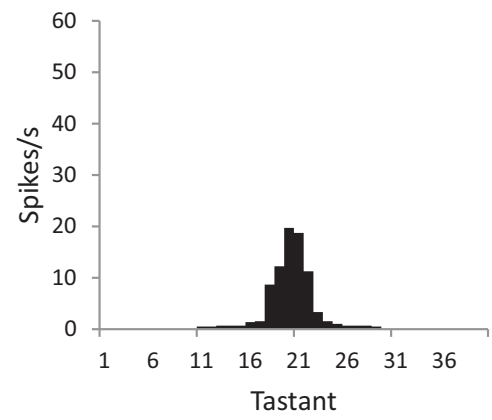

f1a (C)

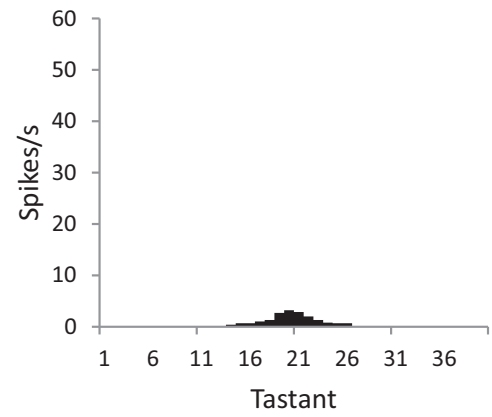

f1d (C)

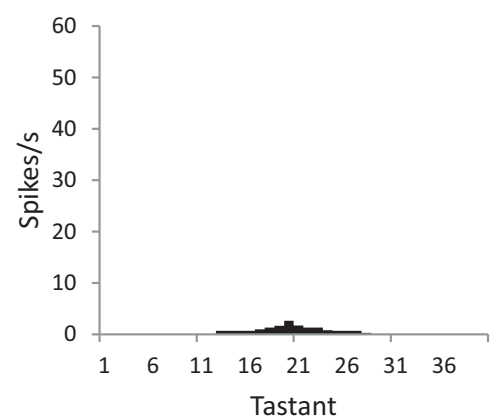

f4s (A2)

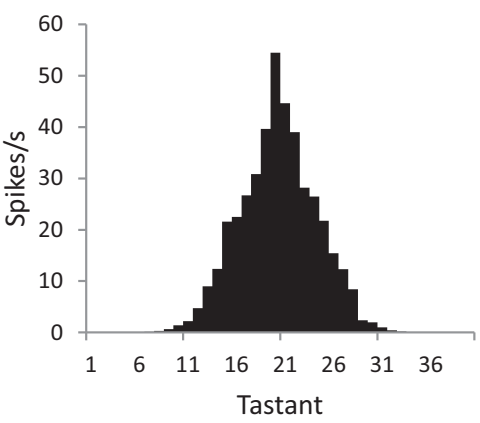

f4b (B)

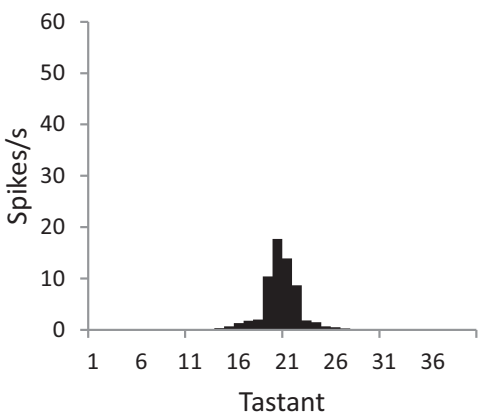

f5a (C)

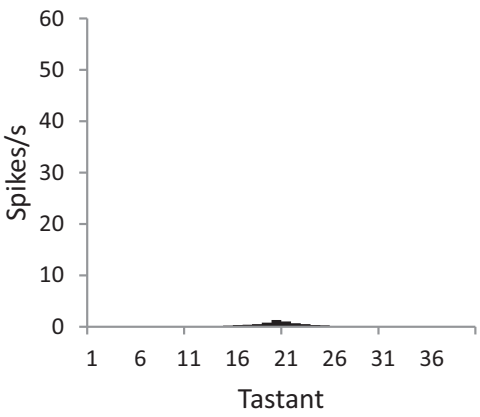

f2a (C)

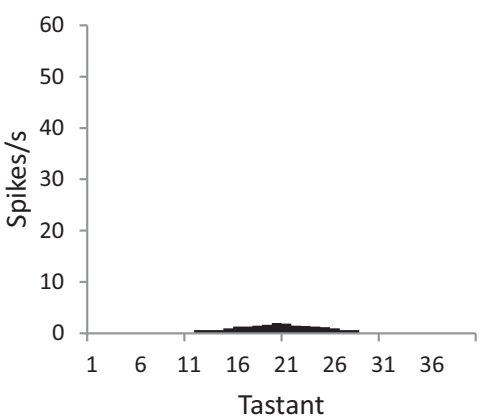

Figure 4. Tarsal sensilla exhibit a wide range of tuning breadths. Sensilla are from the female foreleg. Tuning curves are constructed by arranging the 40 tastants along the $x$-axis according to the magnitude of responses they elicited in each sensilla. The tastants that elicited the strongest responses are placed in the center, and those that elicited the weakest responses are placed near the edges. As a result, the order of tastants is not the same for each sensillum. Data are from Table 2. The functional type of each sensillum is indicated in parentheses (Fig. 5).

sion of the space represents the response of one type of sensillum. If one constructs a four-dimensional space representing these four types of foreleg taste sensilla and if one considers the Euclidean distance between each pair of tastants in this space, then the mean \pm SEM distance between all pairwise combinations of the 15 bitter tastants is $21 \pm 1$ spikes/s $(n=105)$. The space can be represented in three dimensions by applying principal components analysis (Fig. 7). The corresponding mean \pm SEM distance for a five-dimensional space representing the five types of labellar sensilla (Weiss et al., $2011)$ is greater: $32 \pm 1$ spike/s $(n=105 ; p<0.001$, paired $t$ test $)$. In a nine-dimensional space representing combined sensory input from both organs, the mean distance is $40 \pm 1$ spike/s $(n=$ 
A
Distance

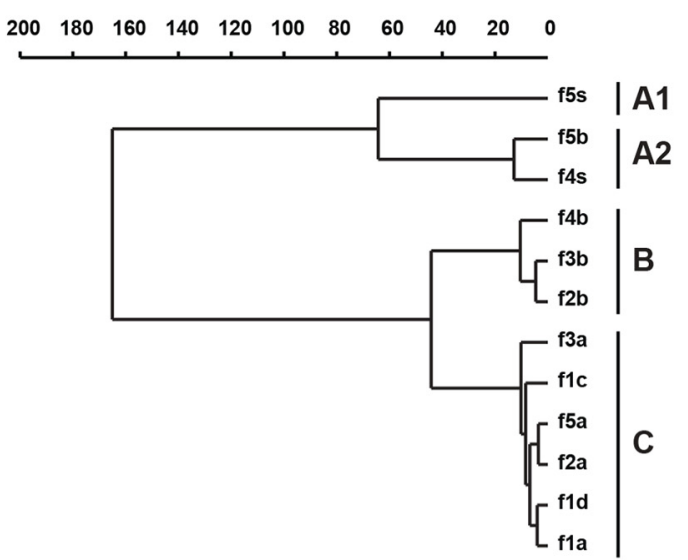

C

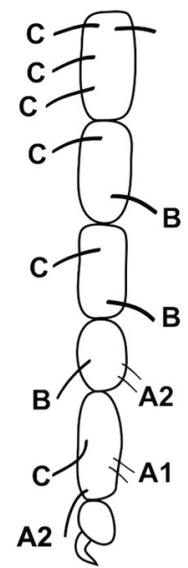

B
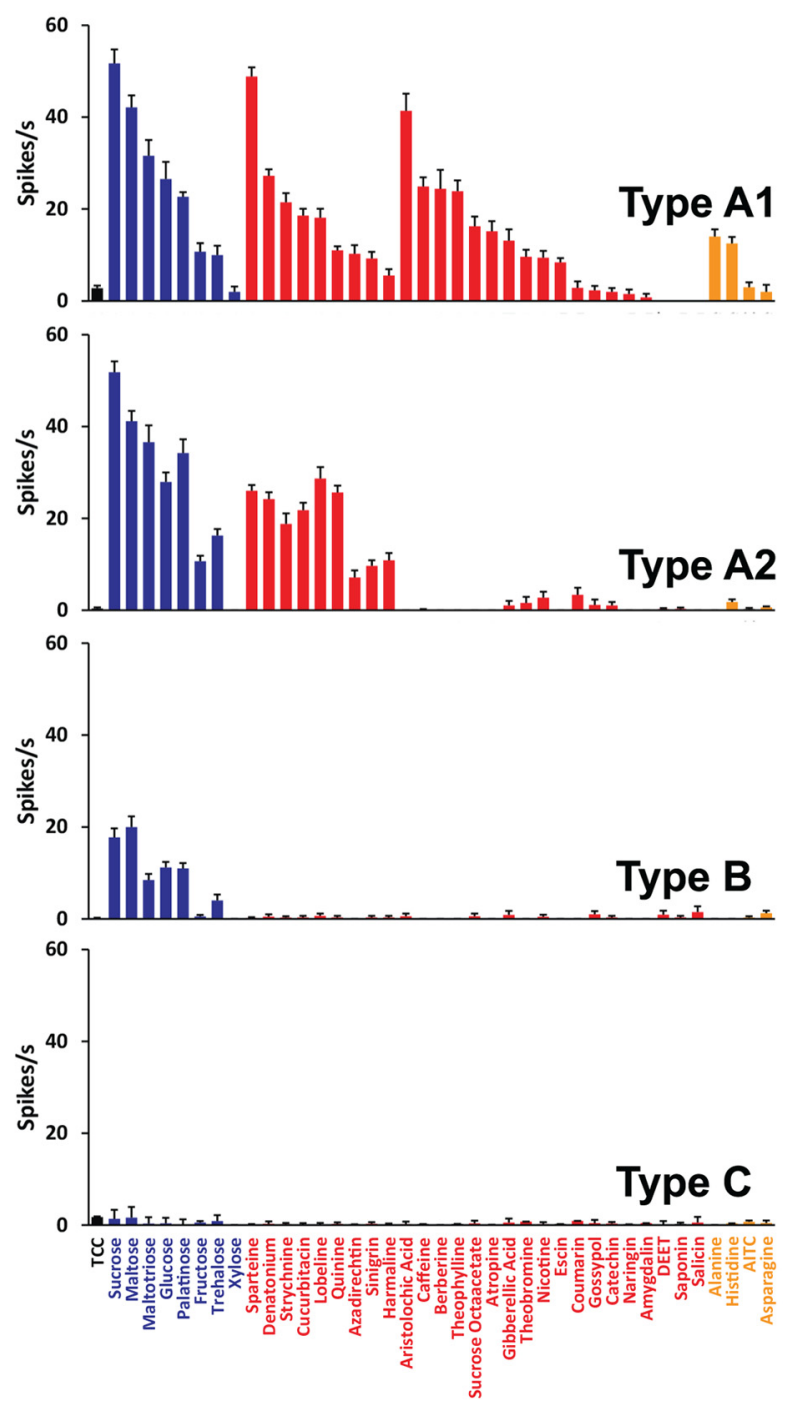

Figure 5. Four functional types of tarsal sensilla on the female foreleg. $\boldsymbol{A}$, Cluster analysis, based on Ward's method, of individual sensilla according to physiological responses. $\boldsymbol{B}$, Mean responses of all sensilla in each of the indicated functional types. Error bars indicate SEM. Tastants are ordered to clarify the differences among sensillar types. Data are from Table 2. Control responses to TCC are small, are shown to the left, and are not subtracted from the means. $C$, Distribution of these four functional types on the female foreleg. Sensilla $\mathrm{f} 1 \mathrm{~b}, \mathrm{f} 4 \mathrm{c}$, and $\mathrm{f} 5 \mathrm{v}$ were not included in this physiological analysis and are unlabeled in the diagram.
105). The greater separation of tastants in the combined space $(p<0.001$ in each case, paired $t$ test) reflects the greater number of sensillum types that results from the evolution of two functionally diverse taste organs.

Finally, we asked whether bitter tastants that are close together in this combined taste space are close in chemical structure. We calculated Euclidean distances between tastants in a 1486dimensional chemical taste space, in which each dimension represents a molecular descriptor of the structure of the tastants. A regression analysis did not reveal a relationship between physiological distances (Fig. 7) and chemical distances $(r=0.14, p>0.05)$. This result provides a striking contrast to the olfactory system, in which comparable analyses reveal much greater $r$ values (Haddad et al., 2008) and may be in part attributable to the extensive coexpression of taste receptors in individual bitter-sensing neurons (Thorne et al., 2004; Wang et al., 2004; Moon et al., 2009; Weiss et al., 2011) as opposed to the expression of only one or a small number of odor receptors in each olfactory receptor neuron (ORN; Su et al., 2009).

\section{Other functional types of sensilla in the} midleg and foreleg

The anatomical organization of the female midleg is similar to that of the foreleg (Fig. 1C). We asked whether the functional organization is also similar. There has been little if any previous physiological or behavioral analysis of the Drosophila midlegs. There are some limited data from a behavioral study of the blowfly Phormia regina (Dethier, 1976) and a study in adult nymphalid butterflies (Omura et al., 2011).

Electrophysiological analysis of the midlegs and hindlegs is severely hampered by their location, which complicates the preparation and makes access to sensilla more difficult, and their length, which reduces the stability of the preparation. We were unable to make recordings from hindlegs but were able to make recordings from midlegs, although with a much reduced success rate. On account of this reduced rate, we focused our analysis on a panel of 15 compounds that distinguish among the four functional types of foreleg sensilla described above.

The physiological responses of midleg sensilla are shown along with responses to the same tastants in the foreleg (including the responses of foreleg sensilla $\mathrm{f} 5 \mathrm{v}$ and $\mathrm{f} 4 \mathrm{c}$ as described below) so as to permit 


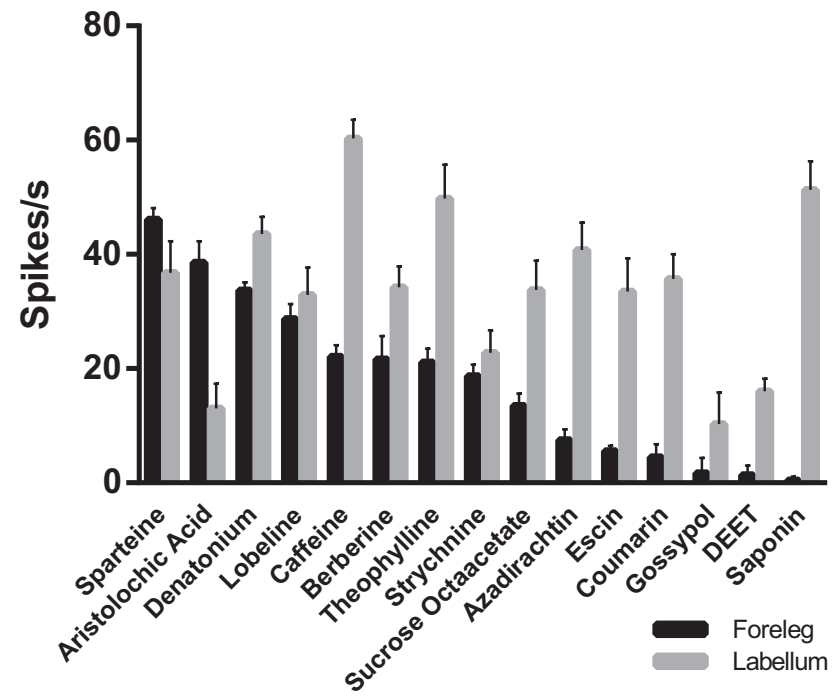

Figure 6. Comparison of the maximum physiological responses to bitter compounds elicited from the labellum and the 14 foreleg sensilla (see below). Each value represents the maximum mean \pm SEM response elicited from an individual sensillum in the legs and labellum for each given tastant. The identity of the sensillum varies for different tastants, e.g., in the labellum, caffeine elicited the greatest response from the $\mathrm{S}_{5}$ sensillum and lobeline elicited the greatest response from the $\mathrm{I}_{3}$ sensillum. Responses to the TCC diluent are subtracted from both labellar and tarsal values (responses were not subtracted in Table 2). The labellar data are from Weiss et al. (2011).

convenient comparison (Fig. 8, Table 3). The midleg contains three sensilla that respond to both sugars and bitter compounds. Their response profiles appear similar to those of $\mathrm{f} 5 \mathrm{~b}$ and $\mathrm{f} 4 \mathrm{~s}$ on the foreleg, although the difference in size of the datasets makes it difficult to establish their correspondence rigorously via a cluster analysis.

Striking differences between the midleg and the foreleg are also apparent. First, the broadly tuned $\mathrm{f} 5 \mathrm{~s}$ is absent in the midleg, and none of the midleg sensilla are so broadly tuned. As a result, the midleg responds to fewer bitter compounds than the foreleg. Second, no type B sensilla (foreleg sensilla $\mathrm{f} 4 \mathrm{~b}, \mathrm{f} 3 \mathrm{~b}$, and $\mathrm{f} 2 \mathrm{~b}$, which give moderate responses to some sugars but no bitter compounds) were identified in the midleg. Rather, a majority of the midleg sensilla responded to none of the tested compounds, in a pattern indistinguishable from the type $\mathrm{C}$ sensilla. These data suggest the possibility that, in the midleg, the type B sensilla are transformed into type C sensilla, thereby losing their sugar responses.

In addition to the 12 pairs of foreleg sensilla described above, we tested two additional foreleg sensilla that were difficult to access, $\mathrm{f} 5 \mathrm{v}$ and $\mathrm{f} 4 \mathrm{c}$, with the limited panel of 15 compounds (Fig. 8 , Foreleg). We observed strong responses to sugar compounds in $\mathrm{f} 5 \mathrm{v}$ of the foreleg, stronger than those in other foreleg sensilla, but this sensillum showed little if any response to bitter compounds. This finding is consistent with data reported in a previous study that used calcium imaging (Miyamoto et al., 2013). The f4c sensillum responded to several bitter compounds, including denatonium and lobeline, but not caffeine, theophylline, or sucrose octaacetate. The response profile of $\mathrm{f} 4 \mathrm{c}$ to bitter compounds resembles that of the A2 sensilla (f5b and $\mathrm{f} 4 \mathrm{~s}$ ). However, $\mathrm{f} 4 \mathrm{c}$ differs from the A2 sensilla in that it shows little if any response to sugars. Thus, the results obtained with this limited tastant panel indicate that the foreleg sensilla $\mathrm{f} 5 \mathrm{v}$ and $\mathrm{f} 4 \mathrm{c}$ constitute two functional types of tarsal sensilla distinct from the four described above, a conclusion supported by a hierarchical cluster analysis (data not shown). Thus, these results bring to six the total number of functional types of sensilla on the foreleg.

\section{Gr-GAL4 expression in the tarsi}

We analyzed expression patterns of all 68 members of the $\mathrm{Gr}$ family in the tarsi of each of the three legs in both male and female flies. We used the GAL4-UAS system, which has been more successful for the analysis of $G r$ gene expression patterns than in situ hybridization, presumably because levels of $G r$ gene expression are low (Clyne et al., 2000; Dahanukar et al., 2001; Dunipace et al., 2001; Scott et al., 2001). We used 67 Gr-GAL4 drivers to represent the 68 receptors (Weiss et al., 2011); one line, Gr23aGAL4, represents two receptors, Gr23a.a. and Gr23a.b, that are encoded by alternatively spliced transcripts sharing a common $5^{\prime}$ region. For most receptors, two independent $G r-G A L 4$ lines were examined.

For each driver, we mapped reporter expression to identified sensilla in the tarsi by following each GFP-labeled dendrite to the shaft of a sensillum using a confocal microscope. We mapped GFP reporter expression in tarsi for $27 \mathrm{Gr}-G A L 4$ drivers (Figs. 9-11). All 27 drivers show expression in the forelegs, with 14 of these drivers showing expression only in the forelegs and 13 in the tarsi of all the legs. None of the drivers are expressed solely in the midlegs or hindlegs. Interestingly, all of the 14 foreleg-restricted Gr-GAL4 drivers are expressed specifically in a single pair of sensilla ( $\mathrm{f} 5 \mathrm{~s} / \mathrm{m} 5 \mathrm{~s}$ ). The overall expression patterns of $\mathrm{Gr}-\mathrm{GAL} 4$ drivers in the midlegs and hindlegs are very similar to each other. We also observed expression in legs of a 28th line, Gr68a-GAL4, in agreement with previous studies (Bray and Amrein, 2003; Ejima and Griffith, 2008), but both neuronal and non-neuronal cells were labeled and the pattern was difficult to interpret with confidence.

Despite differences in organization and function of taste sensilla between the two sexes in the forelegs (Nayak and Singh, 1983; Meunier et al., 2000), we did not observe any sexual dimorphism in the expression of $G r-G A L 4$ drivers other than $G r 68 a$, which has been reported previously to show sexually dimorphic expression in the male foreleg (Bray and Amrein, 2003; Ejima and Griffith, 2008). The rest of the Gr-GAL4 drivers showed similar expression patterns in the two sexes.

Although expression of most of the $G r$ drivers was observed previously in the labellum, expression of Gr68a-GAL4 and Gr58c-GAL4 has not. However, we note that Gr58c-GAL4 also exhibited expression in a small number of enteroendocrine cells in the midgut, which may have chemosensory function (Park and Kwon, 2011). Curiously, Gr58c-GAL4 is not expressed in the sex-specific sensilla of the male forelegs. Instead, it is expressed in the $5 \mathrm{~b}$ and $4 \mathrm{~s}$ sensilla in all three pairs of legs and in the $\mathrm{f} 4 \mathrm{c}$ sensillum of the forelegs, and it showed similar expression patterns in both sexes. However, its expression does not exclude a role in detecting contact pheromones, and in fact $G r 58 c-G A L 4$ is coexpressed with Gr32a-GAL4. Gr32a was reported to regulate male courtship behavior (Miyamoto and Amrein, 2008; Koganezawa et al., 2010; Fan et al., 2013).

\section{A receptor-to-neuron map of the tarsi}

To increase further the resolution of the analysis, we assigned each tarsal Gr-GAL4 driver to individual gustatory receptor neurons (GRNs; Fig. 12). This mapping was based on doublelabeling experiments in males with $G r-G A L 4$ drivers and Gr66a$R F P$ (Fig. 12A), which is a marker of bitter neurons (Thorne et al., 2004; Wang et al., 2004; Marella et al., 2006), and on analysis of GFP reporter expression in flies carrying pairwise combinations 

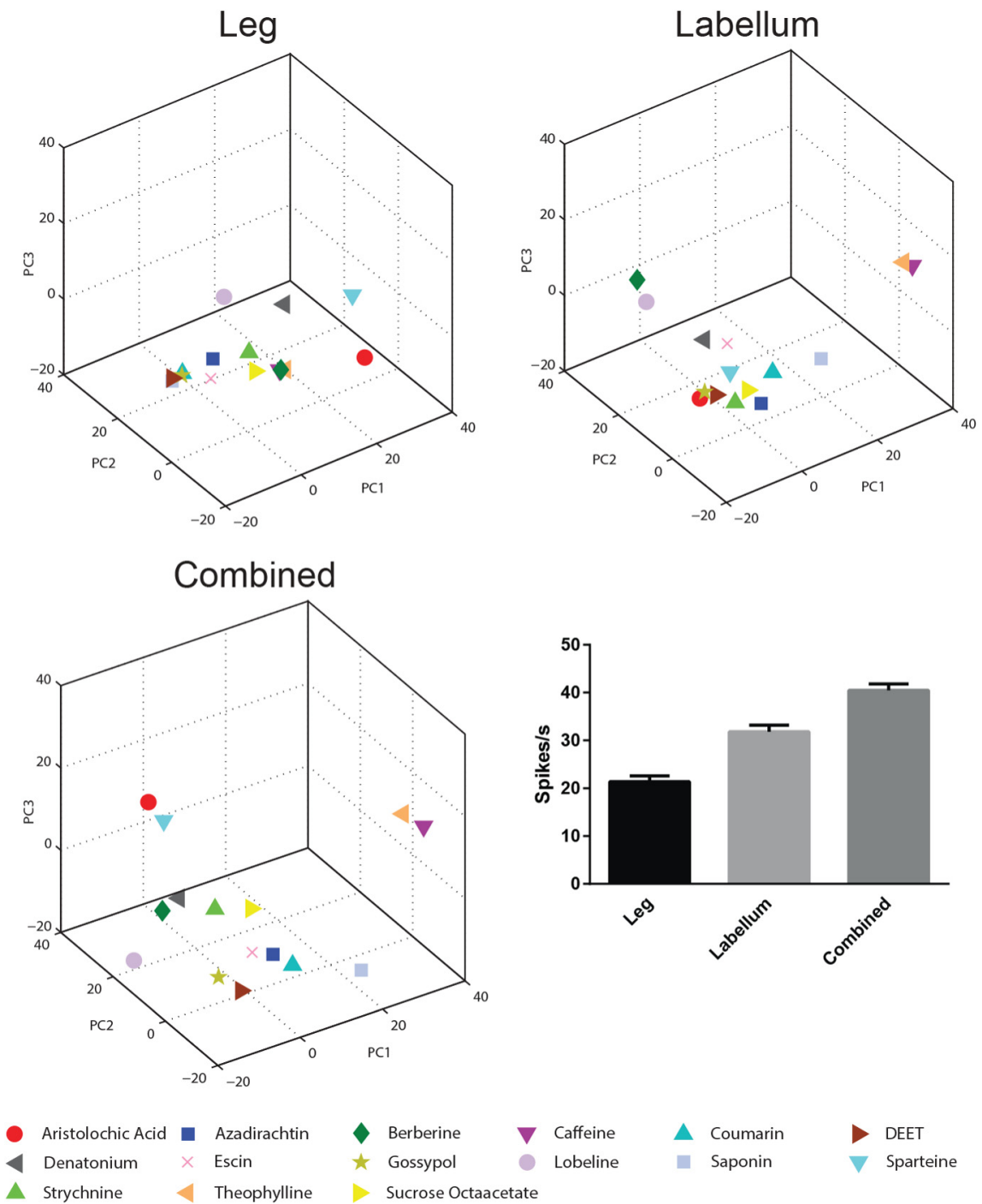

Figure 7. Distribution of tastants in a taste space based on sensillum response. The first three principal components (PC1-PC3) of a foreleg, labellum, and combined space are shown, based on 15 bitter compounds that were tested systematically against all labellar and foreleg tarsal sensilla. The mean Euclidean distances between all pairwise combinations of tastants in each space are shown at the bottom right. The foreleg space is based on the 12 sensilla that have been analyzed in greatest detail.

of drivers ( $n>20$ combinations, including Gr32a-GAL4 combined with Gr33a-GAL4, Gr39a.a-GAL4, Gr58c-GAL4, and Gr89a-GAL4; data not shown).

This analysis generated a receptor-to-neuron map of $\mathrm{Gr}$ GAL4 expression in tarsal sensilla (Fig. 12B). The map identifies six types of sensilla, each distinct from the sensillum types defined for the labellum in terms of Gr-GAL4 expression (Weiss et al., 2011). The types were diverse in their patterns of receptor expression. Two types of sensilla, one comprising $\mathrm{m} 5 \mathrm{~b}$ and $\mathrm{m} 4 \mathrm{~s}$ and the other comprising $\mathrm{m} 5 \mathrm{~s}$, each contain one neuron that expresses bitter receptor drivers, such as Gr66a-GAL4 or Gr33a-GAL4, and one neuron that expresses drivers of genes that belong to a clade of sugar receptors, such as Gr5a-GAL4 (Robertson et al., 2003; Dahanukar et al., 2007; Jiao et al., 2007). Three types of sensilla, collectively including $\mathrm{m} 5 \mathrm{v}, \mathrm{m} 3 \mathrm{~b}, \mathrm{~m} 2 \mathrm{~b}$, and $\mathrm{m} 4 \mathrm{~b}$, contain one neuron that expresses drivers of the sugar receptor clade but do not contain a neuron expressing bitter receptor drivers (with the possible exception of Gr36a-GAL4, which mapped to m5v but could not be mapped to a neuron within this sensillum). The sixth type, containing $\mathrm{m} 4 \mathrm{c}$, is reciprocal, in that it contains a neuron expressing drivers associated with bitter reception but no neuron expressing drivers of the sugar receptor clade.

The bitter-sensing neurons collectively express many receptors. The colabeling analysis suggests the expression of $20 \mathrm{Gr}$ genes in bitter-sensing neurons (Fig. 12B). These results are consistent with mapping in the labellum, in which 17 of these Gr-GAL4 drivers were found coexpressed with Gr66a in bitter-sensing neurons, and they predict that three additional receptors, Gr22c, Gr28b.c, and Gr58c, also function in the recognition of aversive compounds. Thus, at least 20 receptors may act in bitter detection in tarsal taste neurons. Drivers representing three of these, Gr33a, Gr39a.a, and Gr89a, are expressed in every neuron that is labeled by a bitter receptor driver, an observation supported by a broad requirement of $G r 33 a$ for responses to deterrent cues (Moon et al., 2009). Gr33a, Gr39a.a, and Gr89a were proposed to be "core bitter Grs" along with two other receptors because they map to all bitter neurons in the labellum (Weiss et al., 2011).

The tarsal neurons that express bitter receptor drivers show striking variation in molecular complexity. The presumed bitter neuron of the $\mathrm{m} 5 \mathrm{~s}$ sensillum expresses $18 \mathrm{Gr}$ drivers, whereas its counterparts in $\mathrm{m} 5 \mathrm{~b}, \mathrm{~m} 4 \mathrm{~s}$, and $\mathrm{m} 4 \mathrm{c}$ express only five drivers. In contrast, all of the presumed sugar neurons express between three and five drivers.

Drivers of the sugar receptor clade are expressed combinatorially. Gr61a-GAL4 and Gr64f-GAL4 are expressed in all of these combinations, and Gr5a-GAL4 is expressed in most. Of particular interest is the finding that, in $\mathrm{m} 5 \mathrm{v}$, the trehalose receptor driver Gr5a-GAL4 is not expressed, but there is expression of Gr43a-GAL4, representing a highly conserved member of the $G r$ gene family implicated in fructose reception (Sato et al., 2011; Miyamoto et al., 2012; Mishra et al., 2013). Such combinatorial expression is also observed in the labellum (Weiss et al., 2011).

\section{Discussion}

We performed a systematic anatomical, physiological, and molecular analysis of the tarsal sensilla of Drosophila. We constructed an anatomical map of the female tarsal sensilla, including all legs; sensilla on the female foreleg and midleg were tested with a broad panel of compounds, yielding 675 sensillumtastant combinations. We analyzed the expression of all 68 members of the Gr family in tarsal taste sensilla. This integrated study provides insight into the molecular and cellular bases of taste coding in the fly.

The anatomical analysis identified 26, 21, and 22 taste sensilla on the female foreleg, midleg, and hindleg, respectively, in reasonable agreement with previous studies. Most foreleg sensilla exist as bilaterally symmetric pairs on the lateral and medial sides 


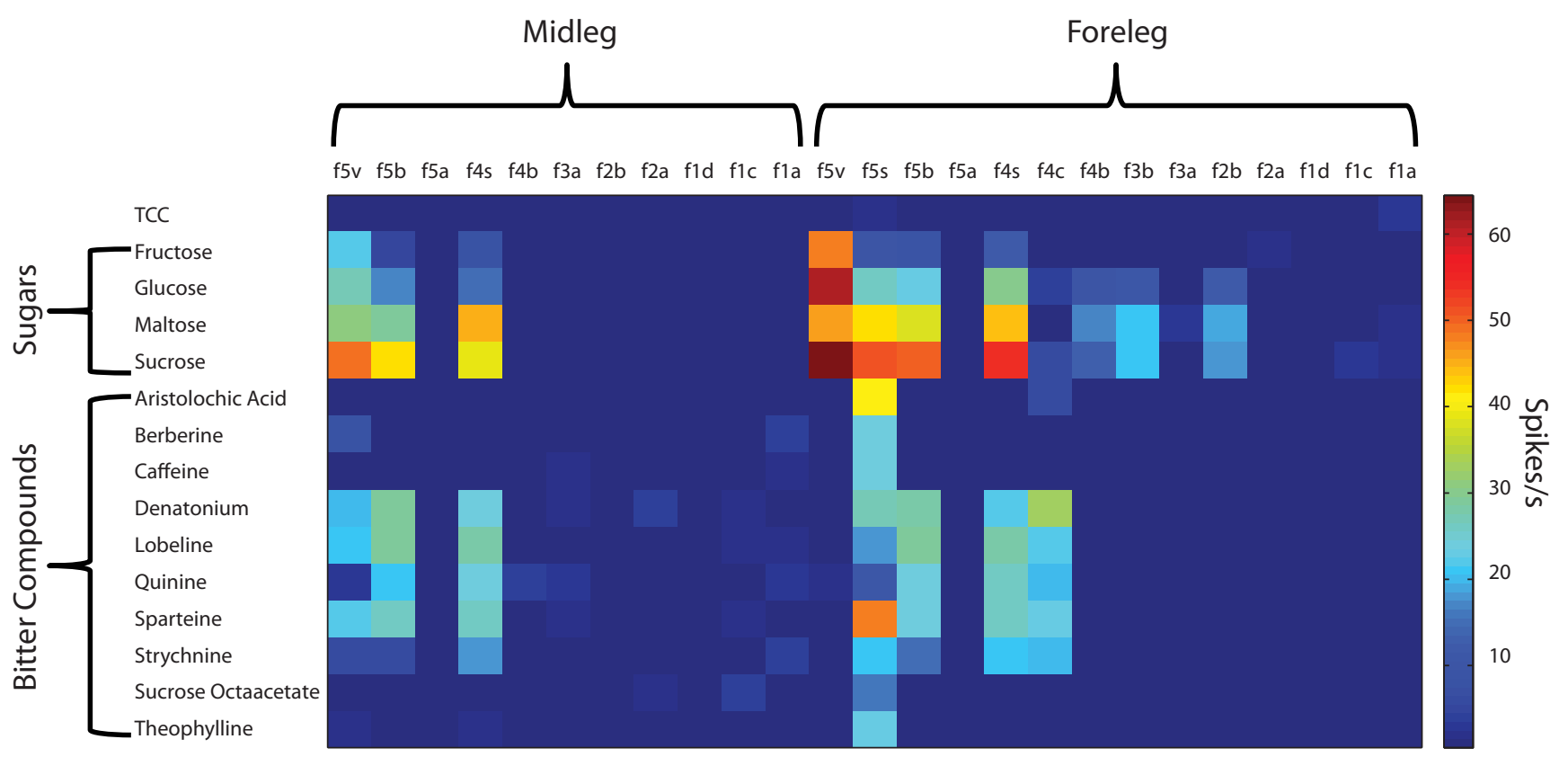

Figure 8. Other functional types of sensilla in the midleg and foreleg. The heat map shows the electrophysiological responses of female midleg tarsal sensilla and the foreleg sensilla f5v and f4c to a panel of 15 tastants. Values represent the mean responses in spikes per second. For each value, $n \geq 7$ for responses $\geq 5 \mathrm{spikes} / \mathrm{s}$; otherwise, $n \geq 3$. Control responses to the TCC were not subtracted. Values for other sensilla of the female foreleg are included for comparison and are taken from Table 3.

Table 3. Responses of other functional types of sensilla in the foreleg and midleg

\begin{tabular}{|c|c|c|c|c|c|c|c|c|c|c|c|c|c|}
\hline & \multicolumn{10}{|c|}{ Midleg } & \multicolumn{3}{|c|}{ Foreleg } \\
\hline & $f 5 v$ & $f 5 b$ & f5a & f4s & $f 4 b$ & f3a & $f 2 b$ & f2a & f1d & f1c & f1a & f5v & $f 4 c$ \\
\hline TCC & $0.3 \pm 0.3$ & $0.0 \pm 0.0$ & $0.5 \pm 0.5$ & $0.0 \pm 0.0$ & $0.0 \pm 0.0$ & $0.0 \pm 0.0$ & $0.0 \pm 0.0$ & $0.0 \pm 0.0$ & $0.0 \pm 0.0$ & $0.0 \pm 0.0$ & $0.0 \pm 0.0$ & $0.0 \pm 0.0$ & $0.0 \pm 0.0$ \\
\hline Fructose & $22.5 \pm 1.5$ & $5.4 \pm 1.6$ & $0.0 \pm 0.0$ & $8.6 \pm 0.9$ & $0.0 \pm 0.0$ & $0.5 \pm 0.5$ & $0.0 \pm 0.0$ & $1.0 \pm 1.0$ & $0.0 \pm 0.0$ & $0.7 \pm 0.7$ & $0.0 \pm 0.0$ & $48.0 \pm 6.4$ & $0.0 \pm 0.0$ \\
\hline Glucose & $27.7 \pm 5.9$ & $17.5 \pm 1.8$ & $0.0 \pm 0.0$ & $15.9 \pm 2.5$ & $0.3 \pm 0.3$ & $0.0 \pm 0.0$ & $1.0 \pm 0.7$ & $0.0 \pm 0.0$ & $0.0 \pm 0.0$ & $0.7 \pm 0.7$ & $0.0 \pm 0.0$ & $61.2 \pm 4.2$ & $4.3 \pm 2.0$ \\
\hline Maltose & $31.8 \pm 2.4$ & $29.5 \pm 2.2$ & $0.5 \pm 0.5$ & $45.5 \pm 7.6$ & $0.0 \pm 0.0$ & $0.0 \pm 0.0$ & $0.0 \pm 0.0$ & $1.5 \pm 1.5$ & $0.0 \pm 0.0$ & $0.7 \pm 0.7$ & $0.0 \pm 0.0$ & $46.2 \pm 2.1$ & $0.0 \pm 0.0$ \\
\hline Sucrose & $49.5 \pm 3.7$ & $42.5 \pm 4.7$ & $0.0 \pm 0.0$ & $39.8 \pm 3.1$ & $0.7 \pm 0.7$ & $0.0 \pm 0.0$ & $0.0 \pm 0.0$ & $1.2 \pm 0.8$ & $0.0 \pm 0.0$ & $0.5 \pm 0.5$ & $0.0 \pm 0.0$ & $91.8 \pm 6.3$ & $6.9 \pm 3.7$ \\
\hline Aristolochic acid & $0.0 \pm 0.0$ & $0.0 \pm 0.0$ & $0.0 \pm 0.0$ & $0.0 \pm 0.0$ & $0.0 \pm 0.0$ & $0.0 \pm 0.0$ & $0.5 \pm 0.5$ & $0.0 \pm 0.0$ & $0.0 \pm 0.0$ & $0.0 \pm 0.0$ & $0.0 \pm 0.0$ & $0.0 \pm 0.0$ & $6.9 \pm 0.0$ \\
\hline Berberine & $8.3 \pm 2.0$ & $0.0 \pm 0.0$ & $0.7 \pm 0.7$ & $0.0 \pm 0.0$ & $0.0 \pm 0.0$ & $0.0 \pm 0.0$ & $0.8 \pm 0.8$ & $0.0 \pm 0.0$ & $0.0 \pm 0.0$ & $0.0 \pm 0.0$ & $4.0 \pm 2.0$ & $0.0 \pm 0.0$ & $0.0 \pm 0.0$ \\
\hline Caffeine & $0.0 \pm 0.0$ & $0.0 \pm 0.0$ & $0.0 \pm 0.0$ & $0.0 \pm 0.0$ & $0.0 \pm 0.0$ & $2.0 \pm 2.0$ & $0.0 \pm 0.0$ & $1.0 \pm 0.7$ & $0.0 \pm 0.0$ & $0.7 \pm 0.7$ & $2.0 \pm 2.0$ & $0.0 \pm 0.0$ & $0.3 \pm 0.3$ \\
\hline Denatonium & $20.0 \pm 1.1$ & $29.7 \pm 2.3$ & $1.0 \pm 0.7$ & $24.4 \pm 2.8$ & $0.0 \pm 0.0$ & $2.0 \pm 2.0$ & $0.0 \pm 0.0$ & $4.7 \pm 2.9$ & $0.0 \pm 0.0$ & $2.0 \pm 2.0$ & $0.0 \pm 0.0$ & $0.0 \pm 0.0$ & $33.7 \pm 1.2$ \\
\hline Lobeline & $21.1 \pm 2.6$ & $29.6 \pm 2.4$ & $0.0 \pm 0.0$ & $28.3 \pm 5.0$ & $0.0 \pm 0.0$ & $0.0 \pm 0.0$ & $0.0 \pm 0.0$ & $0.8 \pm 0.8$ & $0.0 \pm 0.0$ & $2.8 \pm 1.2$ & $2.0 \pm 2.0$ & $0.7 \pm 0.7$ & $22.0 \pm 1$ \\
\hline Quinine & $3.1 \pm 1.3$ & $21.2 \pm 4.3$ & $1.3 \pm 0.7$ & $24.4 \pm 3.2$ & $4.0 \pm 2.7$ & $3.7 \pm 2.3$ & $0.0 \pm 0.0$ & $1.2 \pm 1.2$ & $0.0 \pm 0.0$ & $0.3 \pm 0.3$ & $3.0 \pm 2.4$ & $2.8 \pm 1.5$ & $20.2 \pm 6.3$ \\
\hline Sparteine & $22.0 \pm 5.0$ & $26.7 \pm 2.0$ & $1.5 \pm 1.0$ & $26.0 \pm 1.8$ & $0.4 \pm 0.4$ & $2.0 \pm 1.2$ & $0.0 \pm 0.0$ & $1.3 \pm 0.8$ & $0.4 \pm 0.4$ & $2.7 \pm 2.7$ & $0.0 \pm 0.0$ & $1.1 \pm 0.7$ & $23.9 \pm 3$ \\
\hline Strychnine & $6.3 \pm 2.5$ & $6.5 \pm 2.9$ & $0.0 \pm 0.0$ & $18.4 \pm 2.0$ & $0.0 \pm 0.0$ & $0.0 \pm 0.0$ & $0.0 \pm 0.0$ & $0.0 \pm 0.0$ & $0.0 \pm 0.0$ & $0.5 \pm 0.5$ & $4.0 \pm 2.3$ & $0.0 \pm 0.0$ & $20.0 \pm 3.3$ \\
\hline Sucros & $0.0 \pm 0.0$ & $0.0 \pm 0.0$ & $0.0 \pm 0.0$ & $0.0 \pm 0.0$ & $0.0 \pm 0.0$ & $0.0 \pm 0.0$ & $0.7 \pm 0.7$ & $1.3 \pm 1.3$ & $0.0 \pm 0.0$ & $2.7 \pm 2.7$ & $0.0 \pm 0.0$ & $0.0 \pm 0.0$ & $0.0 \pm 0.0$ \\
\hline Theophylline & $2.8 \pm 2.0$ & $1.8 \pm 1.8$ & $1.2 \pm 1.2$ & $2.4 \pm 1.9$ & $0.0 \pm 0.0$ & $1.0 \pm 0.6$ & $0.0 \pm 0.0$ & $0.0 \pm 0.0$ & $1.7 \pm 1.3$ & $1.5 \pm 1.0$ & $0.0 \pm 0.0$ & $0.0 \pm 0.0$ & $0.0 \pm 0.0$ \\
\hline
\end{tabular}

Values represent the mean \pm SEM responses of spikes per second. For each value, $n \geq 7$ if responses $\geq 5$ spikes $/ s$; otherwise, $n \geq 3$. Control responses to the TCC diluent were not subtracted.

of the leg, and most have counterparts on midlegs and hindlegs. Both exceptions to the foreleg symmetry rule, $\mathrm{f} 1 \mathrm{~b}$ and $\mathrm{f} 4 \mathrm{c}$, are also exceptional in not having counterparts on other legs and in projecting from the leg at an angle that made physiological analysis difficult. It will be interesting to determine whether these sensilla are evolutionary innovations that confer function in a behavior mediated by forelegs, perhaps in courtship, grooming, or in an aggressive behavior, such as boxing, if not in food source evaluation (Phillis et al., 1993; Greenspan and Ferveur, 2000; Chen et al., 2002; Fan et al., 2013).

A very low level of spontaneous firing was observed when TCC was tested alone, without any sugar or bitter compounds. Some ORNs exhibit high levels of spontaneous firing and can be inhibited by some odorants and excited by others (de Bruyne et al., 2001; Raman et al., 2010). Low levels of background firing in tarsal taste neurons may constrain the ability of these neurons to encode tastants via inhibition. However, the low background fir- ing levels in tarsal neurons may enhance the signal-to-noise ratio of their excitatory responses.

A remarkable feature of the Drosophila tarsal taste neurons is their paucity. The tarsal neuron that is most broadly tuned-that detects 19 of 27 bitter compounds-exists as a single bilaterally symmetric pair in the foreleg, and it has no counterparts in the midleg. Thus, the function of alerting the animal to the presence of many potentially toxic compounds may be relegated to a single pair of neurons on each foreleg. We examined other Drosophila species, including pseudoobscura and sechellia, and observed very similar anatomical patterns of sensillar organization (data not shown).

In contrast to the small numbers of tarsal taste neurons, most ORN classes in the Drosophila olfactory system contain tens of members. Moreover, ORNs of a class converge on a single glomerulus, which may increase the signal-to-noise ratio of olfactory transmission (Wilson and Mainen, 2006). In tarsal neurons, the low background firing level may represent an alternative mecha- 


\section{A Female foreleg}

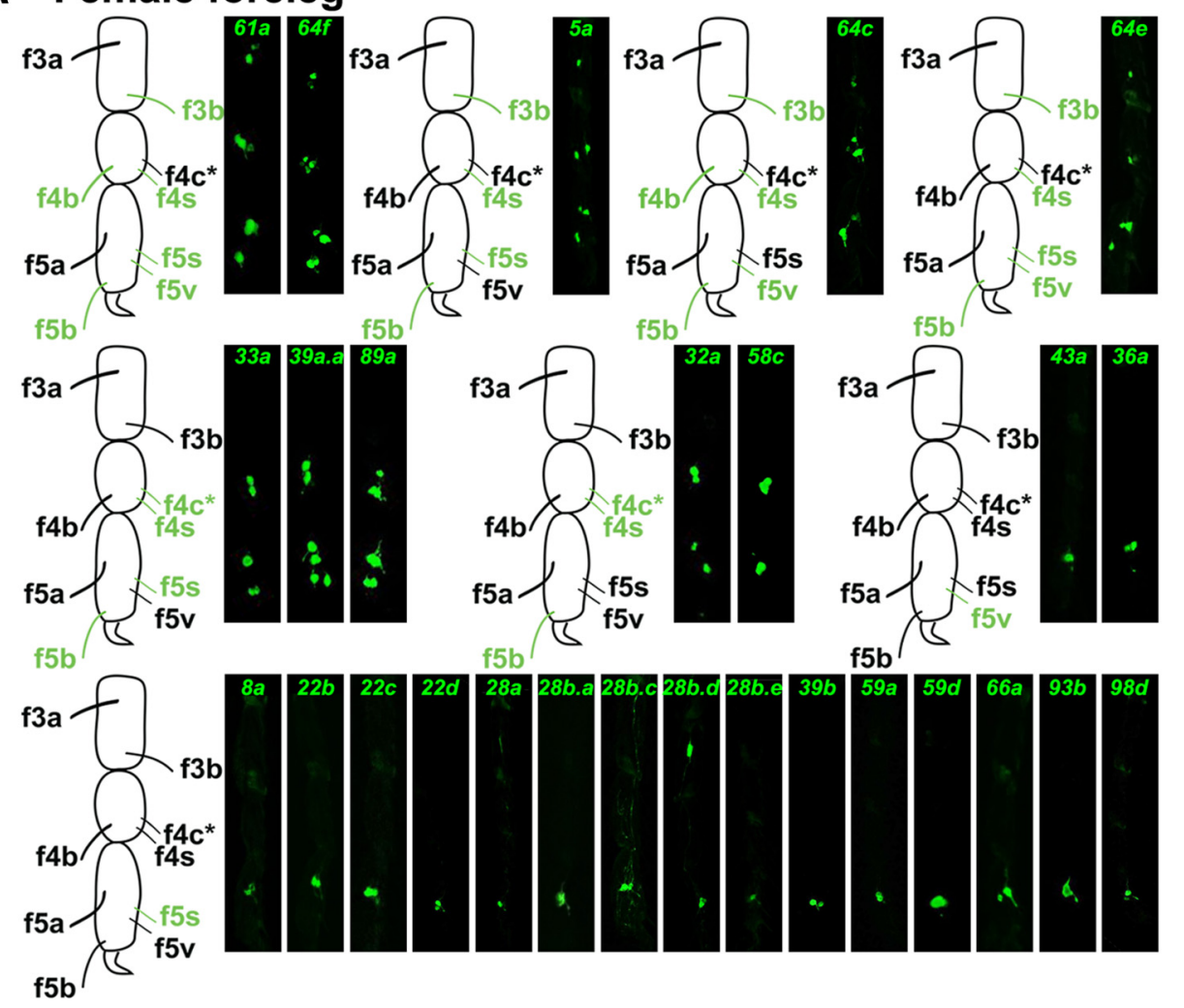

\section{B Male foreleg}
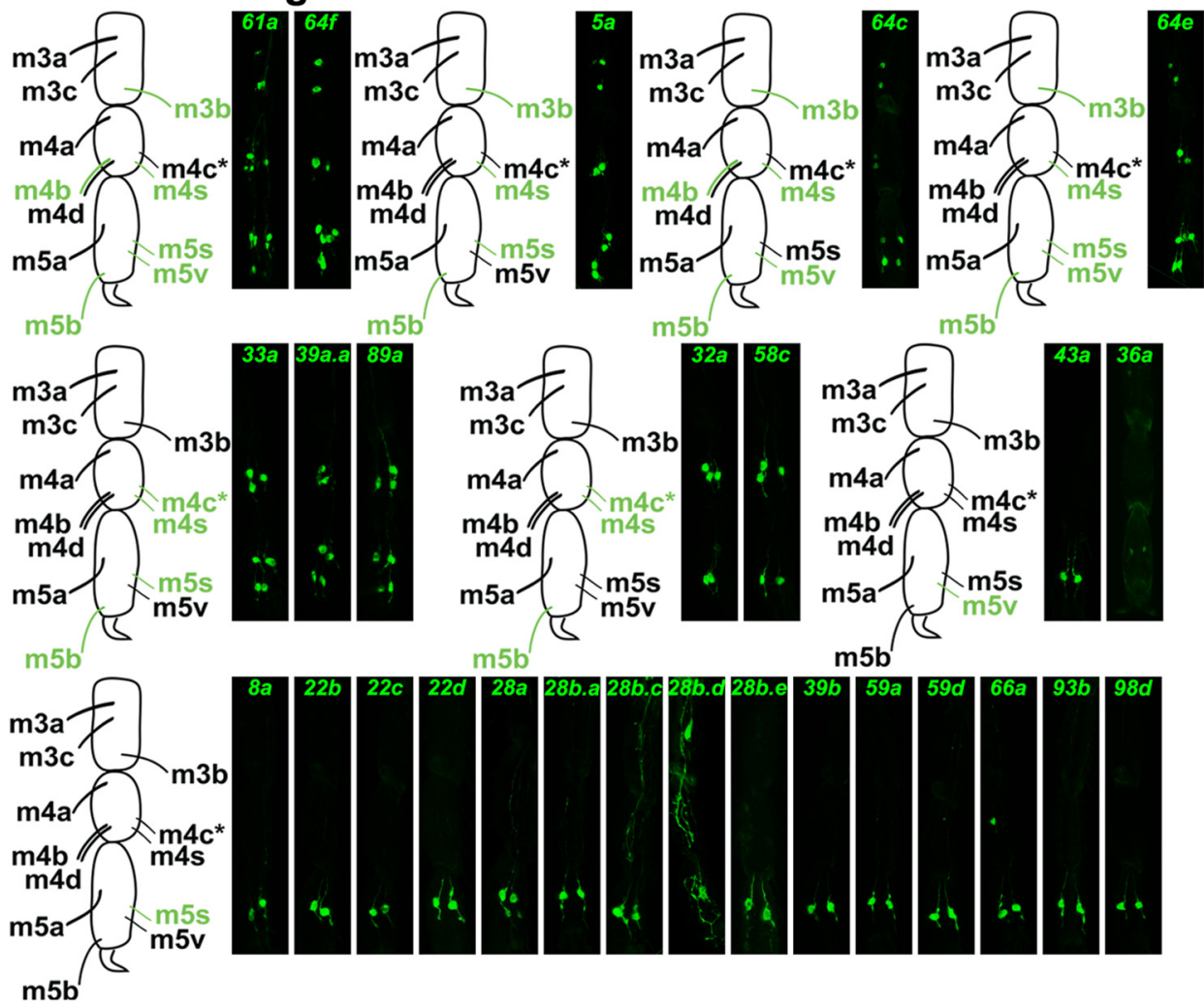

Figure 9. Expression of Gr-GAL4drivers in GRNs of the foreleg. $A$, Compressed z-stacks of single female forelegs showing GFP reporter expression driven by $G r-G A L 4$ constructs. Images were cropped to focus on the three distal tarsomeres (tarsal segments), in which mostGFP expression was observed. GFP expression was also observed in the second tarsomere in a few Gr-GAL4 drivers (Fig. 11). Mostsensilla contain a symmetric counterpart on the opposite side of theleg; depending on theangle of the photograph, labeling of asymmetricsensillum can beviewed in somecases butnotall. $\boldsymbol{B}$, Compressed $z$-stacks ofsinglemale forelegs showing GFP reporter expression of Gr-GAL4drivers. Wenotethat, in some cases, e.g., Gr64fand Gr5a, weoccasionally observewhat appear to betwo cell bodies in thethird tarsomere; it is possiblethatthe cell bodies are the two symmetricsensilla viewed from an angle. Labeling of $\mathrm{m} 5 \mathrm{v}$ by Gr36a-GAL4 was weak. Asterisks indicate sensilla without a symmetric counterpart. 


\section{A Female midleg}

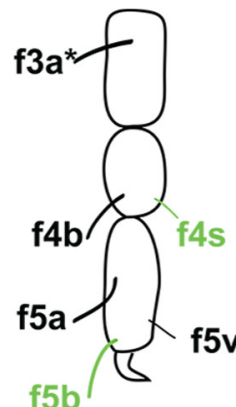

\section{Female hindleg}
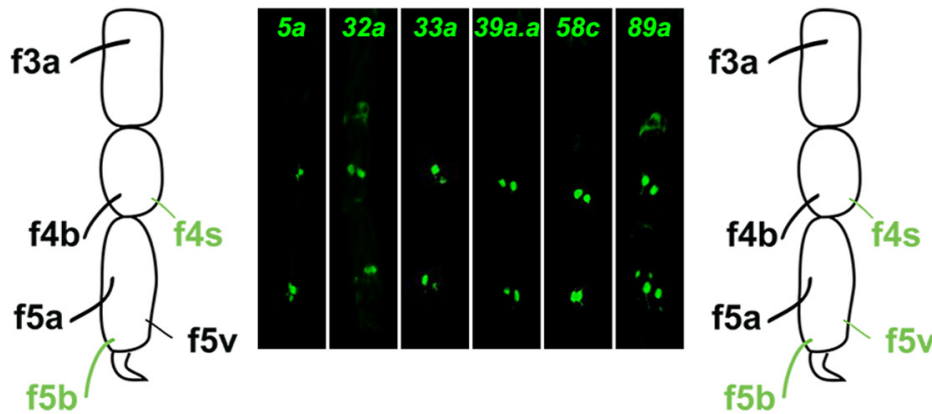
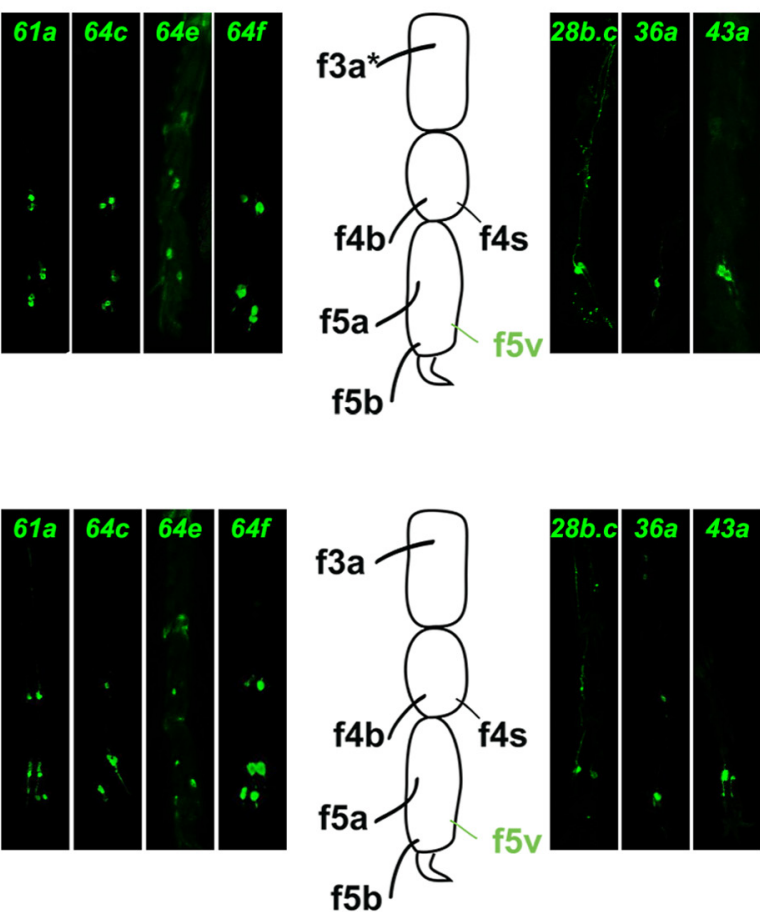

$\mathrm{f} 5 \mathrm{~b}$

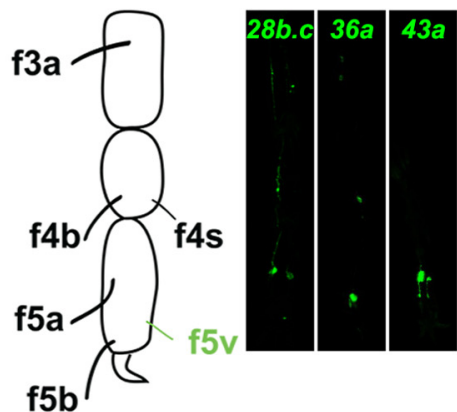

\section{B Male midleg}

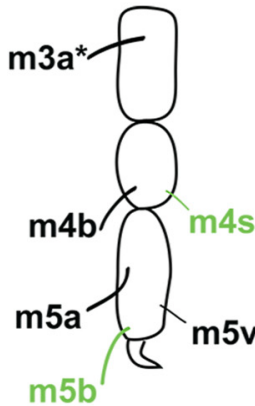

Male hindleg
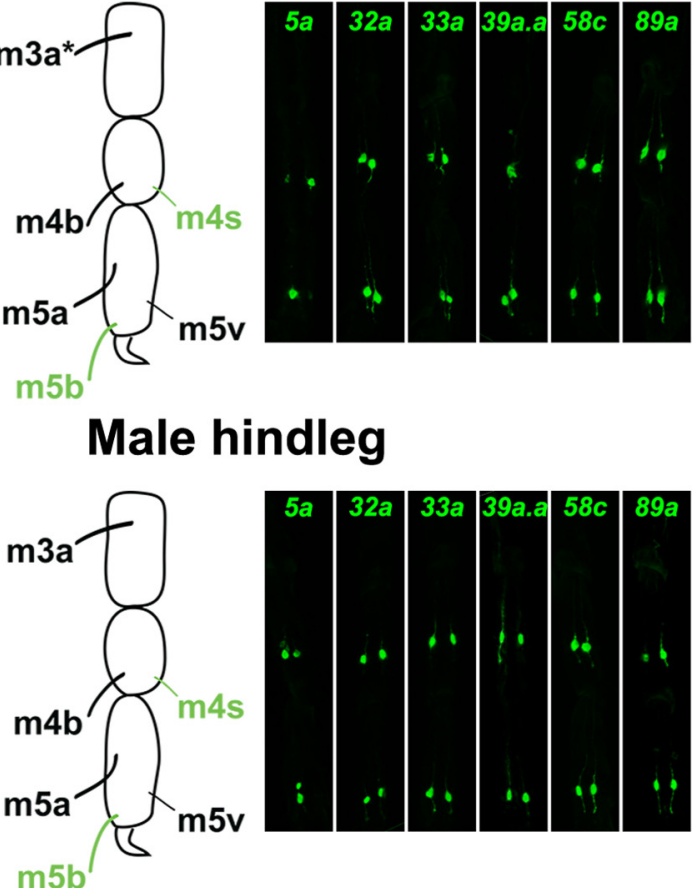
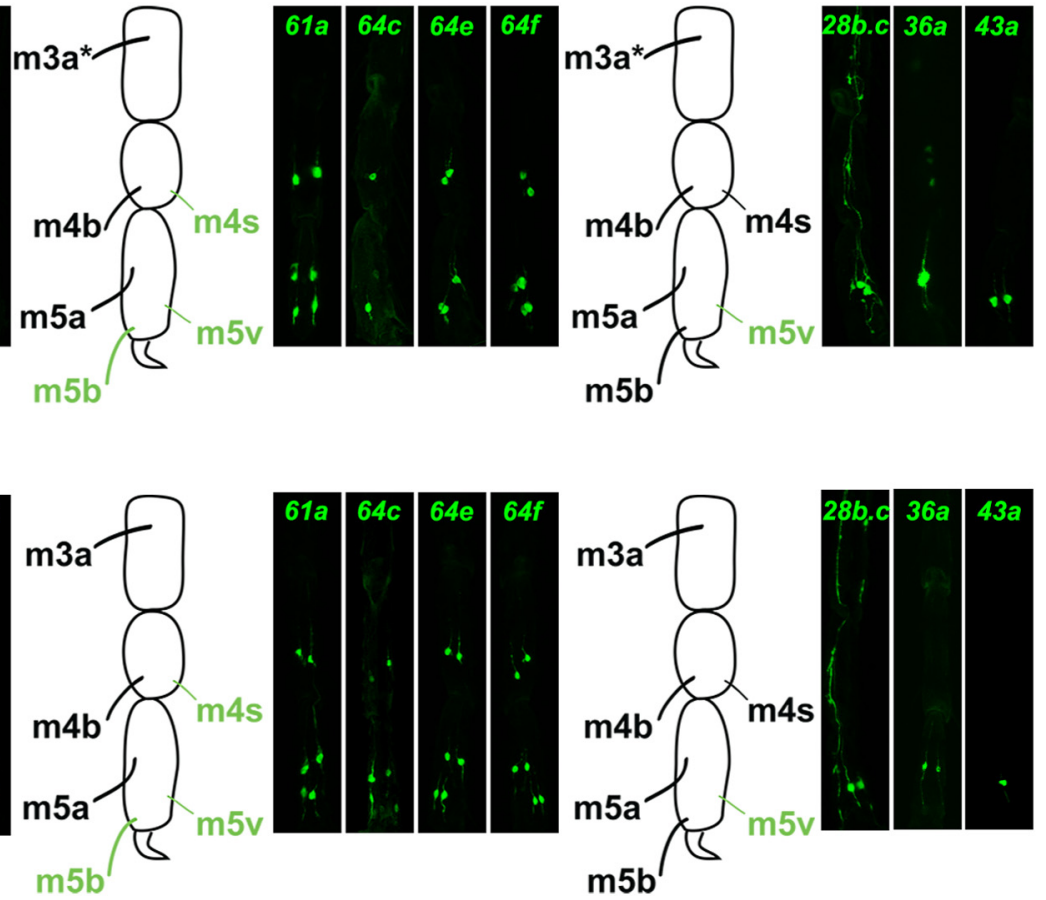

Figure 10. Expression of Gr-GAL4 drivers in GRNs of the midleg and hindleg. $\boldsymbol{A}$, Compressed z-stacks of female midleg and hindleg showing GFP reporter expression of Gr-GAL4 drivers. $\boldsymbol{B}$, Male midleg and hindleg. Asterisks indicate sensilla without a symmetric counterpart.

nism for enhancing the signal-to-noise ratio, in effect compensating for their paucity.

Approximately half of the sensilla analyzed in this study, the type $\mathrm{C}$ sensilla, did not respond to any tested tastants. In contrast, all of 21 labellar sensilla tested responded to sugars (Hiroi et al., 2002). The tarsal type $C$ sensilla are located predominantly in the more proximal tarsal segments, in which they are less likely to make contact with potential food sources, and all are on the dorsal side of the leg, in which they may make contact with other flies. For example, when a male taps a female during courtship, type C sensilla on the male leg may make contact with the female cuticle. Although these sensilla contain four neurons, none responds 


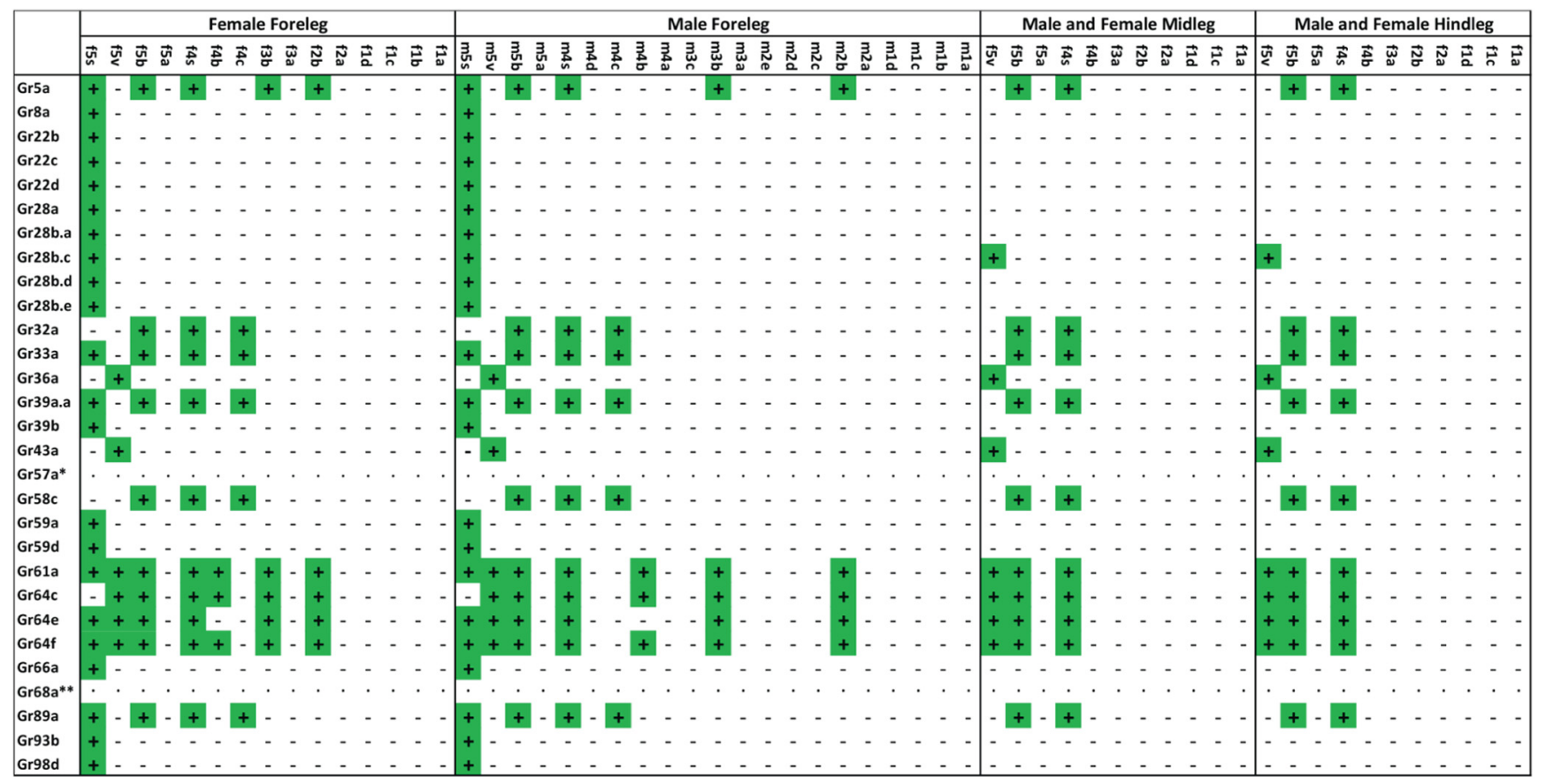

Figure 11. Summary of Gr-GAL4 expression in the legs. Tarsal Gr-GAL4 drivers are mapped to individual sensilla in the three pairs of legs in males and females. Gr-GAL4 expression patterns in the midlegs and hindlegs are identical in male and female flies. + denotes expression of GFP reporter; - indicates no expression; $\bullet$ is used for drivers that are expressed in leg neurons but for which expression has not been mapped. *CNS projection patterns (data not shown) suggest that Gr57a-GAL4 is expressed in the legs, but labeling of tarsal cells was not visualized; ** expression of Gr68a-GAL4 was observed in legs, in agreement with Bray and Amrein (2003) and Ejima and Griffith (2008), but both neuronal and non-neuronal cells were labeled and the pattern was difficult to interpret with confidence.

electrophysiologically to sugars or bitter compounds. These results are at variance with the standard four-neuron model of a taste sensillum, in which the four neurons respond to sugars, bitter compounds or low-salt concentrations, high-salt concentrations, and water, respectively (Rodrigues and Siddiqi, 1978; Fujishiro et al., 1984; Hiroi et al., 2002, 2004). Rather, our physiological results are consistent with a model in which sugar or bitter neurons are replaced in type $\mathrm{C}$ sensilla with neurons that confer an attractive or repulsive response to pheromones, promoting male-female courtship or inhibiting male-male courtship (Bray and Amrein, 2003; Miyamoto and Amrein, 2008; Lu et al., 2012; Thistle et al., 2012; Toda et al., 2012). The electrophysiological methods used in our study are difficult to use with many Drosophila pheromones, which are too hydrophobic to dissolve in the aqueous solution that is commonly used simultaneously for stimulus delivery and recording. Limited testing with DMSO as a solvent (Toda et al., 2012) and the pheromone cis-vaccenyl acetate as a stimulus against all foreleg sensilla did not yield conclusive results in our analysis.

Forelegs are distinct from midlegs in their physiological responses to sugars and bitter compounds. Forelegs contain more distinguishable types of sensilla than midlegs. More foreleg sensilla respond to sugars, and more bitter compounds elicit responses from forelegs. These differences may reflect a different role for the two pairs of legs in feeding behavior, with the forelegs playing an exploratory role and acting, in the case of bitter reception, as an "early warning system." The different response spectra of the two kinds of legs also provide an additional degree of freedom that can in principle expand the capacity of the system to encode taste information.

Overall, the number of distinct patterns of bitter response among tarsal and labellar sensilla is smaller than the number of functional classes of ORNs in the antenna $(\sim 50)$ but comparable with the number of ORN classes in the maxillary palp (six). The maxillary palp is located in close proximity to the labellum and was proposed to act as a close-range olfactory sensor that functions in taste enhancement and that influences feeding decisions (Shiraiwa, 2008).

The functional map constructed in this study raised questions about the molecular basis of taste coding. For example, how, at the molecular level, does one sensillum, f5s, detect more than two-thirds of a structurally diverse set of bitter compounds?

We investigated the molecular basis of taste coding in the legs through a systematic expression analysis of all 68 Grs. Of this large repertoire, drivers representing 20 Grs are expressed in neurons that mediate bitter response (Wang et al., 2004), and these receptors are for convenience referred to as "bitter receptors"; drivers representing six Grs are expressed in neurons that respond to sugar and are referred to as "sugar receptors." The resulting receptor-to-neuron map provides a molecular basis for the coding properties of the neurons. An integrated molecular and functional map (Fig. 13) shows the following: (1) the sensillum that responds to the greatest number of bitter compounds (f5s) expresses the greatest number of bitter receptor drivers; (2) the sensillum that responds to bitter compounds but not sugars (f4c) expresses drivers of bitter receptors but not sugar receptors; (3) the sensilla that respond to sugars but not bitter compounds ( $\mathrm{f} 2 \mathrm{~b}, \mathrm{f3b}$, and $\mathrm{f} 5 \mathrm{v}$ ) express drivers of sugar receptors but not bitter receptors (with the possible exception of Gr36aGAL4 in f5v); (4) the sensilla that respond to both sugars and bitter compounds express both sugar and bitter receptor drivers; and (5) the sensilla that responded to neither sugars nor bitter compounds express none of the $68 \mathrm{Gr}$ drivers.

We acknowledge limitations to the analysis. Some Gr-GAL4 drivers may not reflect expression of the endogenous $G r$ genes in all respects; there are receptors other than Grs that confer gustatory function (Xu et al., 2002; Liu et al., 2003; Cameron et al., 
A
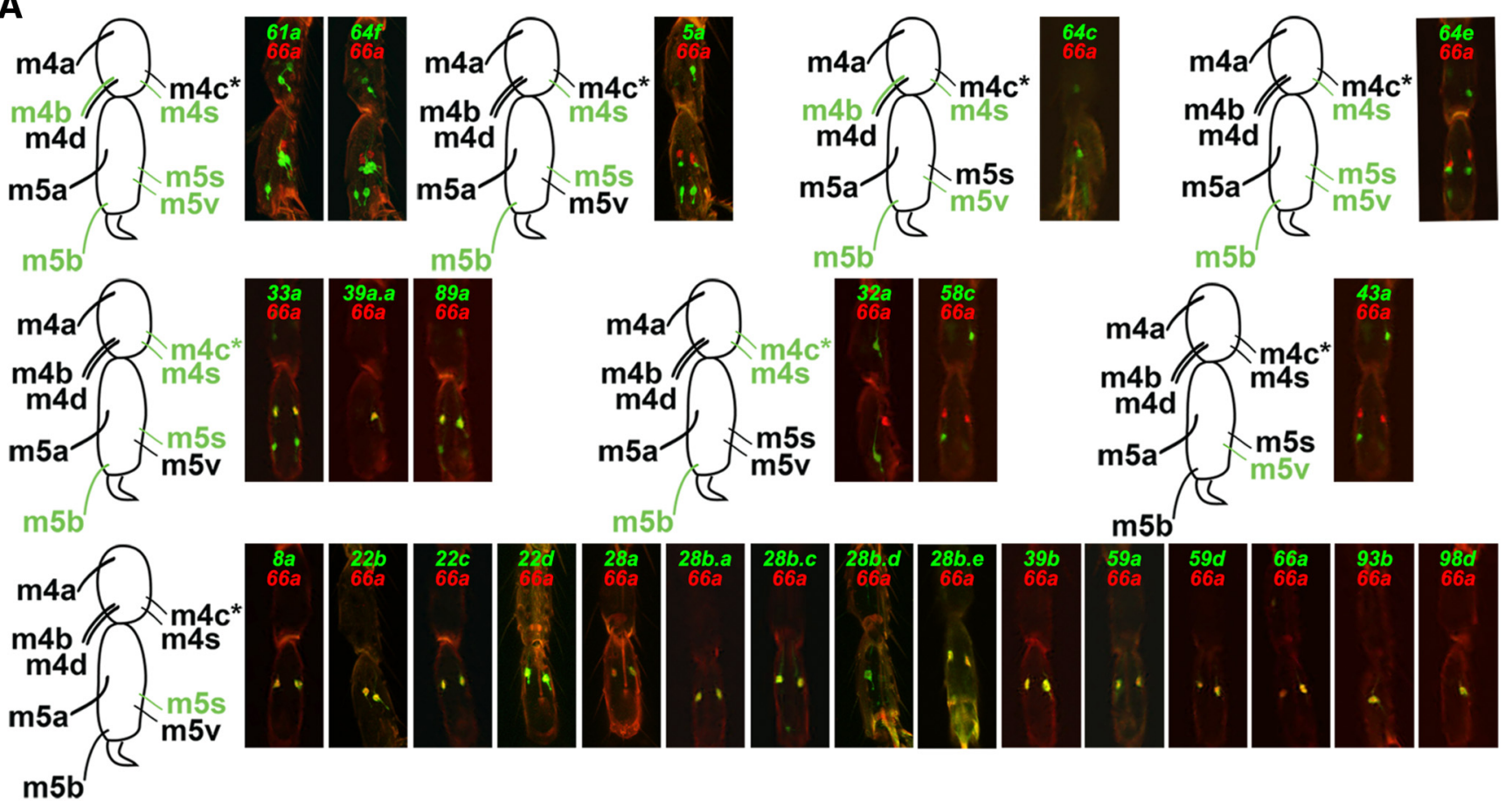

B
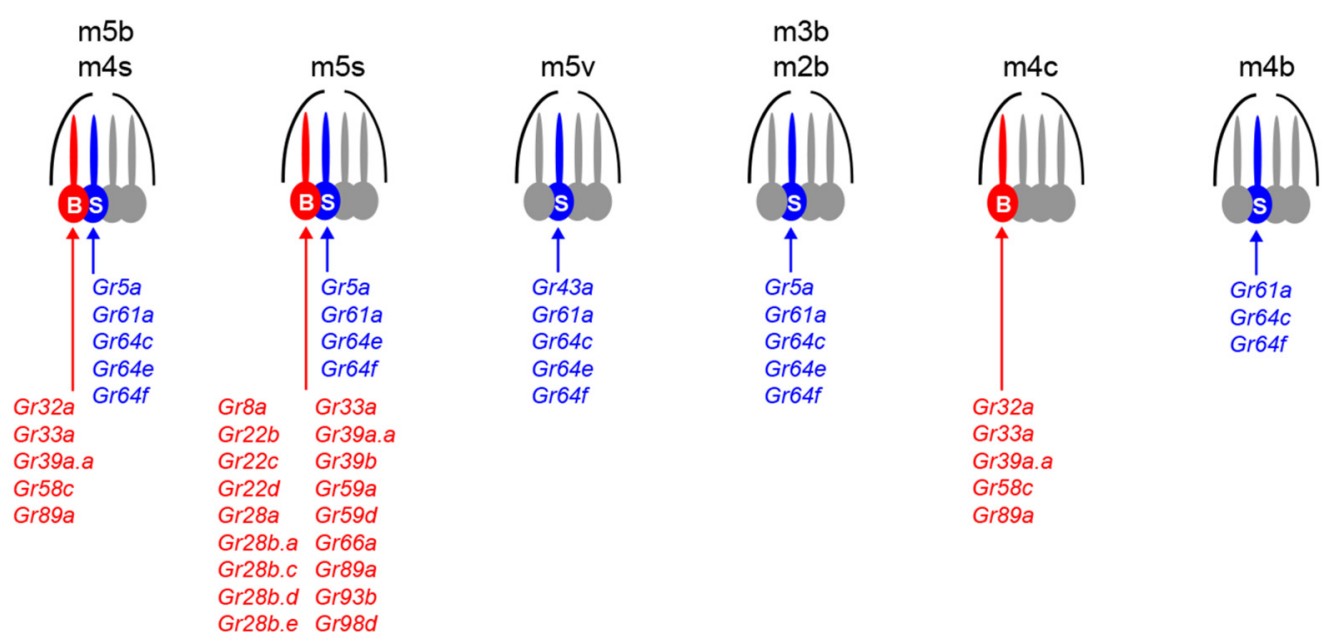

Figure 12. A receptor-to-neuron map of the foreleg tarsi. A, Gr66a-RFP colabeling analysis. Green, Gr-GAL4 expression visualized with a GFP reporter; red, Gr66a-RFP. Colabeling was performed in male flies; only the fourth and fifth tarsomeres are shown because Gr66a-RFP labeling is observed only in the fifth tarsomere and most drivers are expressed in either the fourth or fifth tarsomere. The RFP labeling is weak in some cases (e.g., in the cases of Gr33a and Gr28b.d). The images are optimized to show red/green overlap, and, as a result, some of the GFP-labeled cells are difficult to visualize (e.g., in the cases of Gr64c and Gr39a.a). Asterisks indicate sensilla without a symmetric counterpart. $\boldsymbol{B}$, Receptor-to-neuron map of the forelegs. Gr-GAL4 drivers are assigned to individual GRNs based on their coexpression with Gr66a-RFP and by examining GFP expression in flies carrying pairwise combinations of Gr-GAL4 transgenes ( $n>20$ combinations were tested, including 10 combinations of sugar receptor drivers, 5 combinations of bitter receptor drivers, and 6 combinations of sugar and bitter receptor drivers; data not shown). Gr36a is excluded from the map because of faint expression in the colabeling analysis. Mapping of Gr32a-GAL4 and Gr58c-GAL4, which were not colocalized with Gr66a-RFP, were determined by a pairwise double driver experiment of Gr32a-GAL4 with four other drivers (Gr33a-GAL4, Gr39a.a-GAL4, Gr58c-GAL4, and Gr89a-GAL4).

2010; Croset et al., 2010; Kang et al., 2010; Pikielny, 2010; Zhang et al., 2013); our panel of bitter compounds is necessarily confined to a sampling of tastant space, and more extensive testing could reveal distinctions between GRNs that appear identical in our analysis. We focused on bitter compounds and sugars, which have been shown to signal via Grs, and many other classes of tastants are not considered here.

Our systematic molecular and functional analysis supports fundamental concepts concerning the functional organization of the Drosophila taste system. Both kinds of analysis indicate diversity among taste neurons, among taste sensilla, between forelegs and other legs, and between the legs and labellum. Differential expression of $G r$ genes provides a molecular mechanism to explain much of the functional diversity. The diversity among legs and taste organs may reflect differences in the roles of these organs in feeding behaviors. The molecular and cellular complexity of the taste system revealed in this study may enhance the precision of sensory 


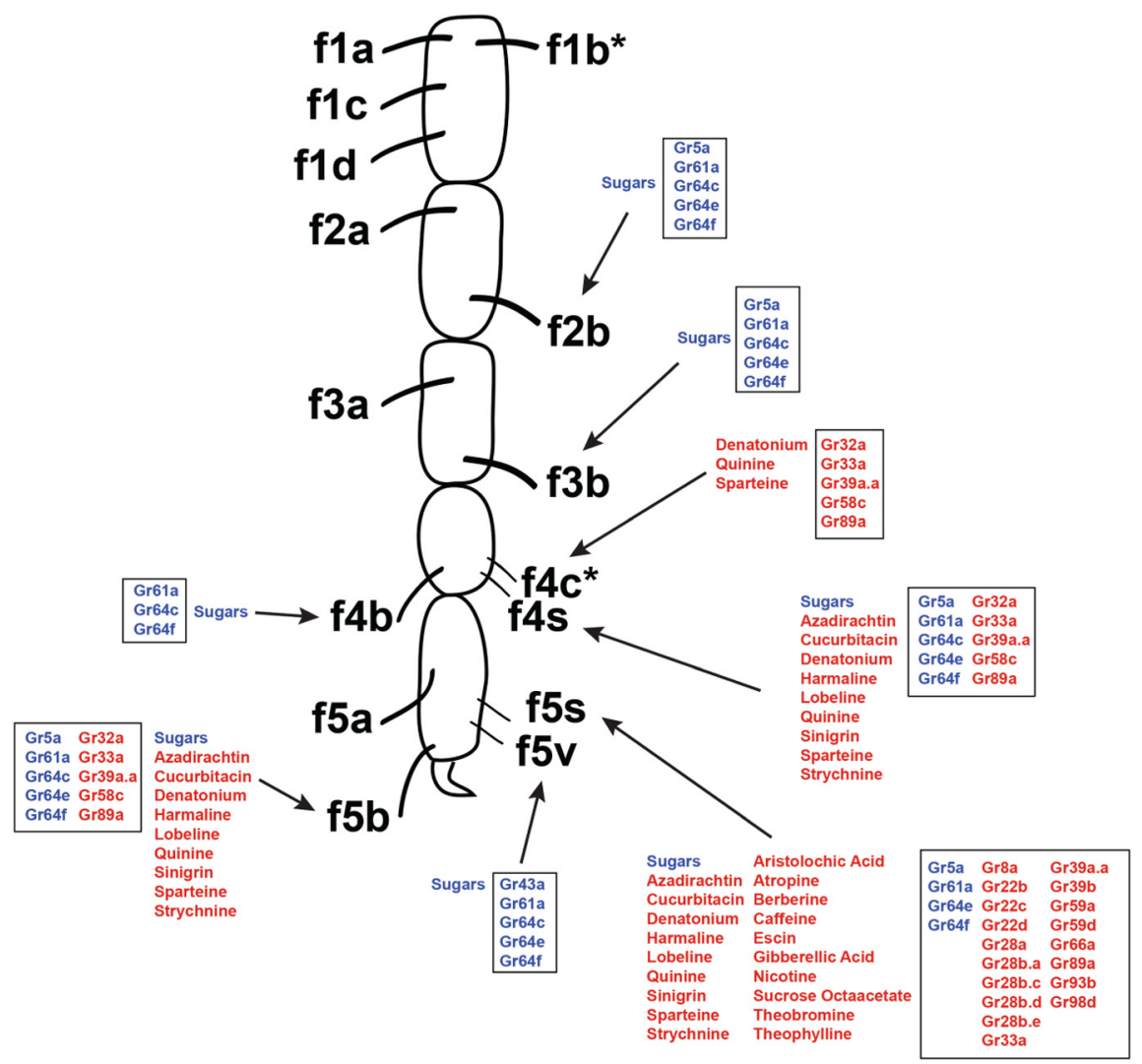

Figure 13. Integrated physiological and molecular maps in the female foreleg. Sugars (blue) and bitter compounds (red) that elicit physiological responses $\geq 5$ spikes/s are listed. Gr-GAL4 drivers are boxed and are indicated in blue if mapped to a sugar neuron or red if mapped to a bitter neuron. We note that, although the maps were constructed in males, Gr-GAL4 expression appeared identical in males and females. Gr36a is excluded from the map because of faint expression in the colabeling analysis. Asterisks indicate sensilla without a symmetric counterpart.

representations and may enrich its behavioral and evolutionary plasticity.

The maps we constructed here may provide a framework for elucidating the molecular basis of response to individual tastants. The maps should also aid in the design of behavioral experiments to test the limits of taste discrimination in the fly (Masek and Scott, 2010); for example, they identify bitter tastants that activate different subsets of sensilla in the foreleg. Finally, they establish a foundation that may be useful in exploring the mechanisms by which a small number of neurons initiates behavior that is essential to the sustenance of life.

\section{References}

Bray S, Amrein H (2003) A putative Drosophila pheromone receptor expressed in male-specific taste neurons is required for efficient courtship. Neuron 39:1019-1029. CrossRef Medline

Brillat-Savarin JA (1825) Physiologie du Goût, ou Méditations de Gastronomie Transcendante; ouvrage théorique, historique et à l'ordre du jour, dédié aux Gastronomes parisiens, par un Professeur, membre de plusieurs sociétés littéraires et savantes. Paris: G. de Gonet.

Cameron P, Hiroi M, Ngai J, Scott K (2010) The molecular basis for water taste in Drosophila. Nature 465:91-95. CrossRef Medline

Chen S, Lee AY, Bowens NM, Huber R, Kravitz EA (2002) Fighting fruit flies: a model system for the study of aggression. Proc Natl Acad Sci U S A 99:5664-5668. CrossRef Medline

Clyne PJ, Warr CG, Carlson JR (2000) Candidate taste receptors in Drosophila. Science 287:1830-1834. CrossRef Medline

Croset V, Rytz R, Cummins SF, Budd A, Brawand D, Kaessmann H, Gibson TJ, Benton R (2010) Ancient protostome origin of chemosensory ionotropic glutamate receptors and the evolution of insect taste and olfaction. PLoS Genet 6:e1001064. CrossRef Medline
Dahanukar A, Foster K, van der Goes van Naters WM, Carlson JR (2001) A Gr receptor is required for response to the sugar trehalose in taste neurons of Drosophila. Nat Neurosci 4:1182-1186. CrossRef Medline

Dahanukar A, Lei YT, Kwon JY, Carlson JR (2007) Two Gr genes underlie sugar reception in Drosophila. Neuron 56:503-516. CrossRef Medline

de Bruyne M, Foster K, Carlson JR (2001) Odor coding in the Drosophila antenna. Neuron 30: 537-552. CrossRef Medline

Dethier VG (1976) The hungry fly. Cambridge, MA: Harvard UP.

Du YJ, Loon JJAV, Renwick JAA (1995) Contact chemoreception of oviposition-stimulating glucosinolates and an oviposition-deterrent cardenolide in two subspecies of Pieris napi. Physiol Entomol 20:164-174. CrossRef

Dunipace L, Meister S, McNealy C, Amrein H (2001) Spatially restricted expression of candidate taste receptors in the Drosophila gustatory system. Curr Biol 11:822-835. CrossRef Medline

Ejima A, Griffith LC (2008) Courtship initiation is stimulated by acoustic signals in Drosophila melanogaster. PLoS One 3:e3246. CrossRef Medline

Falk R, Bleiser-Avivi N, Atidia J (1976) Labellar taste organs of Drosophila melanogaster. J Morphol 150:327-342. CrossRef

Fan P, Manoli DS, Ahmed OM, Chen Y, Agarwal N, Kwong S, Cai AG, Neitz J, Renslo A, Baker BS, Shah NM (2013) Genetic and neural mechanisms that inhibit Drosophila from mating with other species. Cell 154:89-102. CrossRef Medline

Fujishiro N, Kijima H, Morita H (1984) Impulse frequency and action potential amplitude in labellar chemosensory neurones of Drosophila melanogaster. J Insect Physiol 30:317-325. CrossRef

Greenspan RJ, Ferveur JF (2000) Courtship in Drosophila. Annu Rev Genet 34:205-232. CrossRef Medline

Haddad R, Khan R, Takahashi YK, Mori K, Harel D, Sobel N (2008) A metric for odorant comparison. Nat Methods 5:425-429. CrossRef Medline

Hammer O, Harper DAT, Ryan PD (2001) PAST: paleontological statistics software package for education and data analysis. Palaeontol Electronica 4:9.

Hiroi M, Marion-Poll F, Tanimura T (2002) Differentiated response to sugars among labellar chemosensilla in Drosophila. Zoolog Sci 19:1009_ 1018. CrossRef Medline

Hiroi M, Meunier N, Marion-Poll F, Tanimura T (2004) Two antagonistic gustatory receptor neurons responding to sweet-salty and bitter taste in Drosophila. J Neurobiol 61:333-342. CrossRef Medline

Hodgson ES, Lettvin JY, Roeder KD (1955) Physiology of a primary chemoreceptor unit. Science 122:417-418. CrossRef Medline

Jiao Y, Moon SJ, Montell C (2007) Drosophila gustatory receptor required for the responses to sucrose, glucose, and maltose identified by mRNA tagging. Proc Natl Acad Sci U S A 104:14110-14115. CrossRef Medline

Kang K, Pulver SR, Panzano VC, Chang EC, Griffith LC, Theobald DL, Garrity PA (2010) Analysis of Drosophila TRPA1 reveals an ancient origin for human chemical nociception. Nature 464:597-600. CrossRef Medline

Koganezawa M, Haba D, Matsuo T, Yamamoto D (2010) The shaping of male courtship posture by lateralized gustatory inputs to male-specific interneurons. Curr Biol 20:1-8. CrossRef Medline

Liu L, Leonard AS, Motto DG, Feller MA, Price MP, Johnson WA, Welsh M) (2003) Contribution of Drosophila DEG/ENaC genes to salt taste. Neuron 39:133-146. CrossRef Medline

Lu B, LaMora A, Sun Y, Welsh MJ, Ben-Shahar Y (2012) ppk23-Dependent chemosensory functions contribute to courtship behavior in Drosophila melanogaster. PLoS Genet 8:e1002587. CrossRef Medline

Ma CW, Schoonhoven LM (1973) Tarsal contact chemosensory hairs of the 
large white butterfly Pieris brassicae and their possible role in oviposition behaviour. Entomol Exp Appl 16:343-357. CrossRef

Marella S, Fischler W, Kong P, Asgarian S, Rueckert E, Scott K (2006) Imaging taste responses in the fly brain reveals a functional map of taste category and behavior. Neuron 49:285-295. CrossRef Medline

Masek P, Scott K (2010) Limited taste discrimination in Drosophila. Proc Natl Acad Sci U S A 107:14833-14838. CrossRef Medline

Meunier N, Ferveur JF, Marion-Poll F (2000) Sex-specific non-pheromonal taste receptors in Drosophila. Curr Biol 10:1583-1586. CrossRef Medline

Meunier N, Marion-Poll F, Rospars JP, Tanimura T (2003) Peripheral coding of bitter taste in Drosophila. J Neurobiol 56:139-152. CrossRef Medline

Mishra D, Miyamoto T, Rezenom YH, Broussard A, Yavuz A, Slone J, Russell DH, Amrein H (2013) The molecular basis of sugar sensing in Drosophila larvae. Curr Biol 23:1466-1471. CrossRef Medline

Miyamoto T, Amrein H (2008) Suppression of male courtship by a Drosophila pheromone receptor. Nat Neurosci 11:874-876. CrossRef Medline

Miyamoto T, Slone J, Song X, Amrein H (2012) A fructose receptor functions as a nutrient sensor in the Drosophila brain. Cell 151:1113-1125. CrossRef Medline

Miyamoto T, Chen Y, Slone J, Amrein H (2013) Identification of a Drosophila glucose receptor using $\mathrm{Ca}^{2+}$ imaging of single chemosensory neurons. PLoS One 8:e56304. CrossRef Medline

Montell C (2009) A taste of the Drosophila gustatory receptors. Curr Opin Neurobiol 19:345-353. CrossRef Medline

Moon SJ, Lee Y, Jiao Y, Montell C (2009) A Drosophila gustatory receptor essential for aversive taste and inhibiting male-to-male courtship. Curr Biol 19:1623-1627. CrossRef Medline

Nayak SV, Singh RN (1983) Sensilla on the tarsal segments and mouthparts of adult Drosophila melanogaster meigen (Diptera: Drosophilidae). Int J Insect Morphol Embryol 12:273-291. CrossRef

Omura H, Honda K, Asaoka K, Inoue TA (2011) Divergent behavioral and electrophysiological taste responses in the mid-legs of adult butterflies, Vanessa indica and Argyreus hyperbius. J Insect Physiol 57:118-126. CrossRef Medline

Ozaki K, Ryuda M, Yamada A, Utoguchi A, Ishimoto H, Calas D, Marion-Poll $\mathrm{F}$, Tanimura T, Yoshikawa H (2011) A gustatory receptor involved in host plant recognition for oviposition of a swallowtail butterfly. Nat Commun 2:542. CrossRef Medline

Park JH, Kwon JY (2011) Heterogeneous expression of Drosophila gustatory receptors in enteroendocrine cells. PLoS One 6:e29022. CrossRef Medline

Phillis RW, Bramlage AT, Wotus C, Whittaker A, Gramates LS, Seppala D, Farahanchi F, Caruccio P, Murphey RK (1993) Isolation of mutations affecting neural circuitry required for grooming behavior in Drosophila melanogaster. Genetics 133:581-592. Medline

Pikielny CW (2010) Drosophila CheB proteins involved in gustatory detection of pheromones are related to a human neurodegeneration factor. Vitam Horm 83:273-287. CrossRef Medline

Raman B, Joseph J, Tang J, Stopfer M (2010) Temporally diverse firing pat- terns in olfactory receptor neurons underlie spatiotemporal neural codes for odors. J Neurosci 30:1994-2006. CrossRef Medline

Robertson HM, Warr CG, Carlson JR (2003) Molecular evolution of the insect chemoreceptor gene superfamily in Drosophila melanogaster. Proc Natl Acad Sci U S A 100 [Suppl 2]:14537-14542. Medline

Rodrigues V, Siddiqi O (1978) Genetic analysis of chemosensory pathway. Proc Indian Acad Sci B 87:147-160.

Ryuda M, Calas-List D, Yamada A, Marion-Poll F, Yoshikawa H, Tanimura T, Ozaki K (2013) Gustatory sensing mechanism coding for multiple oviposition stimulants in the swallowtail butterfly, Papilio xuthus. J Neurosci 33:914-924. CrossRef Medline

Sato K, Tanaka K, Touhara K (2011) Sugar-regulated cation channel formed by an insect gustatory receptor. Proc Natl Acad Sci U S A 108: 11680-11685. CrossRef Medline

Scott K, Brady R Jr, Cravchik A, Morozov P, Rzhetsky A, Zuker C, Axel R (2001) A chemosensory gene family encoding candidate gustatory and olfactory receptors in Drosophila. Cell 104:661-673. CrossRef Medline

Shiraiwa T (2008) Multimodal chemosensory integration through the maxillary palp in Drosophila. PLoS One 3:e2191. CrossRef Medline

Su CY, Menuz K, Carlson JR (2009) Olfactory perception: receptors, cells, and circuits. Cell 139:45-59. CrossRef Medline

Thistle R, Cameron P, Ghorayshi A, Dennison L, Scott K (2012) Contact chemoreceptors mediate male-male repulsion and male-female attraction during Drosophila courtship. Cell 149:1140-1151. CrossRef Medline

Thorne N, Chromey C, Bray S, Amrein H (2004) Taste perception and coding in Drosophila. Curr Biol 14:1065-1079. CrossRef Medline

Toda H, Zhao X, Dickson BJ (2012) The Drosophila female aphrodisiac pheromone activates ppk23(+) sensory neurons to elicit male courtship behavior. Cell Rep 1:599-607. CrossRef Medline

Wang Z, Singhvi A, Kong P, Scott K (2004) Taste representations in the Drosophila brain. Cell 117:981-991. CrossRef Medline

Weiss LA, Dahanukar A, Kwon JY, Banerjee D, Carlson JR (2011) The molecular and cellular basis of bitter taste in Drosophila. Neuron 69:258-272. CrossRef Medline

Wieczorek H, Wolff G (1989) The labellar sugar receptor of Drosophila. J Comp Physiol A Neuroethol Sens Neural Behav Physiol 164:825-834. CrossRef

Wilson RI, Mainen ZF (2006) Early events in olfactory processing. Annu Rev Neurosci 29:163-201. CrossRef Medline

Xu A, Park SK, D’Mello S, Kim E, Wang Q, Pikielny CW (2002) Novel genes expressed in subsets of chemosensory sensilla on the front legs of male Drosophila melanogaster. Cell Tissue Res 307:381-392. CrossRef Medline

Zhang YF, van Loon JJA, Wang CZ (2010) Tarsal taste neuron activity and proboscis extension reflex in response to sugars and amino acids in Helicoverpa armigera (Hübner). J Exp Biol 213:2889-2895. CrossRef Medline

Zhang YF, Huang LQ, Ge F, Wang CZ (2011) Tarsal taste neurons of Helicoverpa assulta (Guenee) respond to sugars and amino acids, suggesting a role in feeding and oviposition. J Insect Physiol 57:1332-1340. CrossRef Medline

Zhang YV, Ni J, Montell C (2013) The molecular basis for attractive salttaste coding in Drosophila. Science 340:1334-1338. CrossRef Medline 